\title{
High-resolution quantitative precipitation forecasts and simulations by the Cloud-Resolving Storm Simulator(CReSS) for Typhoon Morakot (2009)
}

\author{
Chung-Chieh Wang a,*, Hung-Chi Kuo ${ }^{\mathrm{b}}$, Tien-Chiang Yeh ${ }^{\mathrm{c}}$, Chao-Hsuan Chung ${ }^{\mathrm{a}}$, Yu-Han Chen ${ }^{\mathrm{a}, \mathrm{b}}$, \\ Shin-Yi Huang ${ }^{\text {a,b }}$, Yi-Wen Wang ${ }^{a}$, Ching-Hwang Liu ${ }^{\text {d }}$ \\ a Department of Earth Sciences, National Taiwan Normal University, Taipei, Taiwan, ROC \\ ${ }^{\mathrm{b}}$ Department of Atmospheric Sciences, National Taiwan University, Taipei, Taiwan, ROC \\ ${ }^{\mathrm{C}}$ Central Weather Bureau, Taipei, Taiwan, ROC \\ ${ }^{\mathrm{d}}$ Department of Atmospheric Sciences, Chinese Culture University, Taipei, Taiwan, ROC
}

\section{A R T I C L E I N F O}

\section{Article history:}

Available online $\mathrm{xxxx}$

\section{Keywords:}

Typhoon

Morakot (2009)

Quantitative precipitation forecasts (QPFs)

Cloud-resolving model

Topography

Taiwan

\begin{abstract}
S U M M A R Y
Typhoon Morakot (2009) struck Taiwan during 7-9 August 2009, and brought extreme rainfall up to $2855 \mathrm{~mm}$ and the worst damages in the past 50 years. The operational models showed deficiency and serious under-prediction in rainfall amount at real time. This study demonstrates that the Cloud-Resolving Storm Simulator (CReSS), a state-of-the-art, high-resolution model, at a grid size of $3 \mathrm{~km}$ and starting as early as 0000 UTC 4 August, can successfully simulate and reproduce the event with high accuracy, including the distribution and timing of heavy rainfall in Taiwan. In the simulation starting at 0000 UTC 6 August, for example, the threat scores for 24-h rainfall for 8 August (with extreme amounts $>1450 \mathrm{~mm}$ ) reach $0.8-0.4$ even at thresholds of $100-500 \mathrm{~mm}$. This result is only possible due to small track error and the phase-locking mechanism of the Taiwan topography to heavy rainfall.

Furthermore, real-time forecast and hindcast integrations of the CReSS model show that high-quality quantitative precipitation forecasts (QPFs) with peak total amount $67-80 \%$ of the true value are also obtained from initial conditions at 0000 UTC 6 August, which is about 2 days prior to the beginning of the heaviest rainfall in southern Taiwan. In these integrations, typhoon track errors in the global model forecasts used as boundary conditions are the major error source that prevent more ideal QPF results before and at 1200 UTC 5 August. When properly configured, it is believed that other similar cloudresolving models can achieve comparable performance. Thus, the importance of and potential benefits from deterministic high-resolution forecasts is stressed, which may give an extended lead-time when the track error is small. With potentially longer time window for emergency action just prior to extreme rainfall events when it matters the most, such forecasts may ultimately lead to reduced losses in lives and properties.
\end{abstract}

(c) 2013 Elsevier B.V. All rights reserved.

\section{Introduction and case overview}

Situated over the western North Pacific (WNP), Taiwan (cf. Fig. 1) is hit on average by 3.7 typhoons annually (Wu and Kuo, 1999). When a tropical cyclone (TC) moves close by or makes landfall, the steep and complex topography of Taiwan, especially the north-south aligned Central Mountain Range (CMR) that peaks at almost $4 \mathrm{~km}$ (Fig. 2), can exert strong impacts on rainfall (e.g., Chang et al., 1993; Wu and Kuo, 1999; Cheung et al., 2008). Enhanced uplift of the moisture-laden air in the TC circulation by the terrain of Taiwan thus acts to dictate the rainfall pattern on

* Corresponding author. Address: Department of Earth Sciences, National Taiwan Normal University, No. 88, Sec. 4, Ting-Chou Rd., Taipei 11677, Taiwan, ROC. Tel.: +8862 7734 6399; fax: +886229333315.

E-mail address: cwang@ntnu.edu.tw (C.-C. Wang). the windward slopes and significantly increase the total amount by a factor of 2-3 (e.g., Wu et al., 2002; Lee et al., 2006). Thus, TCs can bring extreme rainfall to Taiwan as shown by many previous events (e.g., Wu et al., 2002; Lee et al., 2008; Chien et al., 2008; Jian and Wu, 2008; Yang et al., 2008). Because of the strong orographic influence, accurate TC track forecasts are crucial for predicting extreme rainfall events in Taiwan.

Typhoon Morakot (TY0908) during 7-9 August 2009 was the most devastating TC to strike Taiwan in over 50 years, with a death toll of 757 and direct damages of more than US\$3.8 billion (http:// www.hurricanescience.org; Hendricks et al., 2011). The peak rainfall amount in Morakot reached $2855 \mathrm{~mm}$ in 4 days in Taiwan, which surpassed all other TCs on record. Based on the Joint Typhoon Warning Center (JTWC) best-track, Morakot became a tropical storm (TS) on 3 August and reached TY status $\left(\geqslant 32.7 \mathrm{~m} \mathrm{~s}^{-1}\right)$ at 1200 UTC 5 August, and then moved nearly due west to approach 


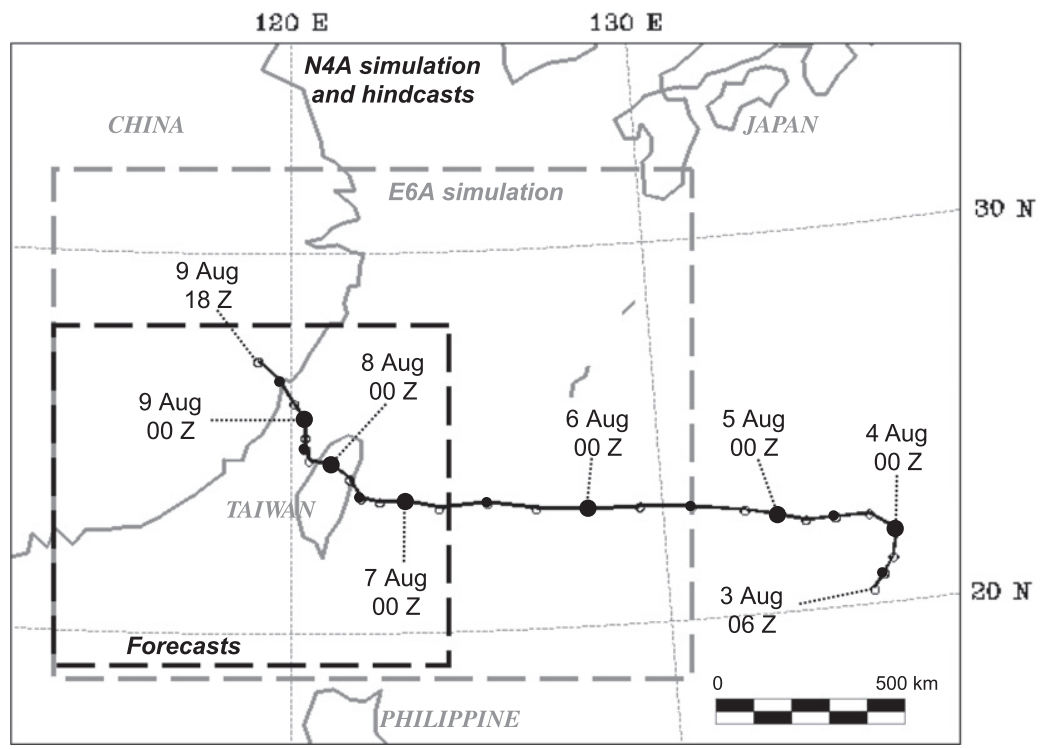

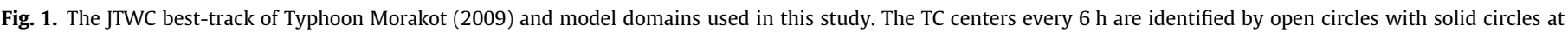
1200 UTC and enlarged solid circles at 0000 UTC, which are also labeled.

Taiwan at a speed of $\geqslant 20 \mathrm{~km} \mathrm{~h}^{-1}$ (Fig. 1). When Morakot moved close to the island on 7 August, it slowed down significantly to $10-15 \mathrm{~km} \mathrm{~h}^{-1}$, and made landfall near 1800 UTC while turning toward the north-northwest (NNW). On 8 August as Morakot was leaving Taiwan during the post-landfall period, it further slowed down to only about $5 \mathrm{~km} \mathrm{~h}^{-1}$ and almost stalled (Fig. 1). Thus, the torrential rain in Taiwan continued until after 0600 UTC 9 August. Chien and Kuo (2011) estimated the total duration of influence from Morakot was thus lengthened to about $64 \mathrm{~h}$, and its slow translation speed near Taiwan was clearly a key factor contributing to the unprecedented, record-breaking rainfall.

Hong et al. (2010) and Ge et al. (2010) suggest that Morakot (2009) was embedded in a large-scale monsoon gyre, which was about $4000 \mathrm{~km}$ in size and included two other TCs, Goni, and Etau. They assert that the interaction of Morakot with its slowly varying (at periods of 10-30 days and longer) background flow determined the basic track of the TC (i.e., first westward then toward the NNW) and the slow translation near Taiwan (cf. Fig. 1). Another factor is the southwest monsoon surge with abundant moisture supply (e.g., Chien and Kuo, 2011; Wu et al., 2011; Liang et al., 2011; Nguyen and Chen, 2011).

Wang et al. (2012) recently show that the feedback from the asymmetric rainfall distribution of Morakot (e.g., Chien and Kuo, 2011; Liang et al., 2011) contributed to a further slow down in its motion to about $5 \mathrm{~km} \mathrm{~h}^{-1}$ on 8 August after landfall in Taiwan. Other factors that may have contributed to the heavy rainfall include a large TC size with strong outer circulation (e.g., Jou et al., 2010), strong moisture flux convergence and repeated rainband formation upstream from southern Taiwan (e.g., Chen et al., 2010; Kuo et al., 2010; Chien and Kuo, 2011), and again the topographic enhancement of rainfall (Ge et al., 2010; Fang et al., 2011; Huang et al., 2011). Note that many of these factors are linked to the background flow and/or storm track, and thus are inter-related via complex and nonlinear interactions.

Reflectivity composites of vertical maximum-echo indicator (VMI) from operational radars in Taiwan and the 850-hPa winds every 6 or $12 \mathrm{~h}$ are shown in Fig. 3. Most of the deep convection was concentrated in the southern to eastern quadrants of the TC center throughout the period of influence. Among those associated with the TC circulation, two persistent rainbands are evident. The first is aligned north-south along the windward side of southern
CMR (south of about $23.7^{\circ} \mathrm{N}$ ) that was produced by topographic enhancement as the TC circulation impinges on the terrain from the west (Fig. 3a-h). The other rainband is nearly east-west oriented and slow-moving across southwestern Taiwan (Fig. 3c-h). Kuo et al. (2010), Chien and Kuo (2011), and Wu et al. (2011) suggest that cells in this rainband formed repeatedly due to the strong low-level convergence between the TC circulation and southwesterly monsoon flow. These intense and persistent rainbands largely contributed to the daily maximum rainfall that started to increase

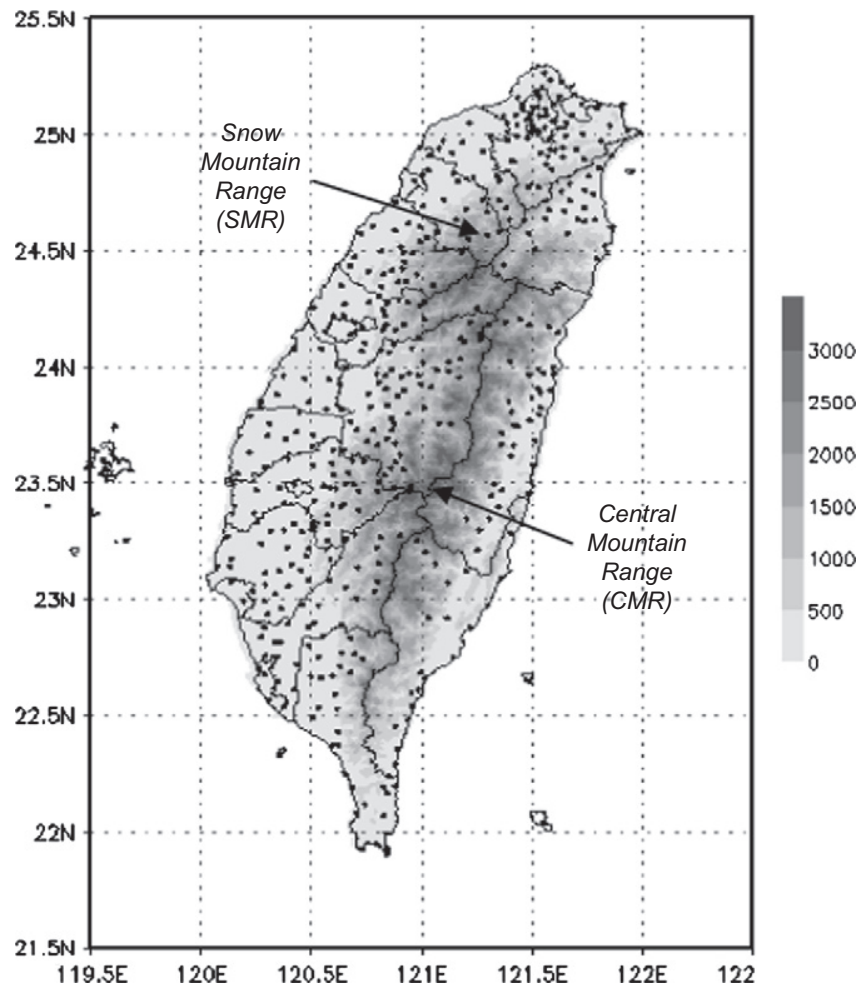

Fig. 2. Topography of Taiwan ( $\mathrm{m}$, shading) and locations of rain-gauge stations (solid dots). The two major mountain ranges in Taiwan, the Central Mountain Range (CMR) and Snow Mountain Range (SMR), are labeled. 

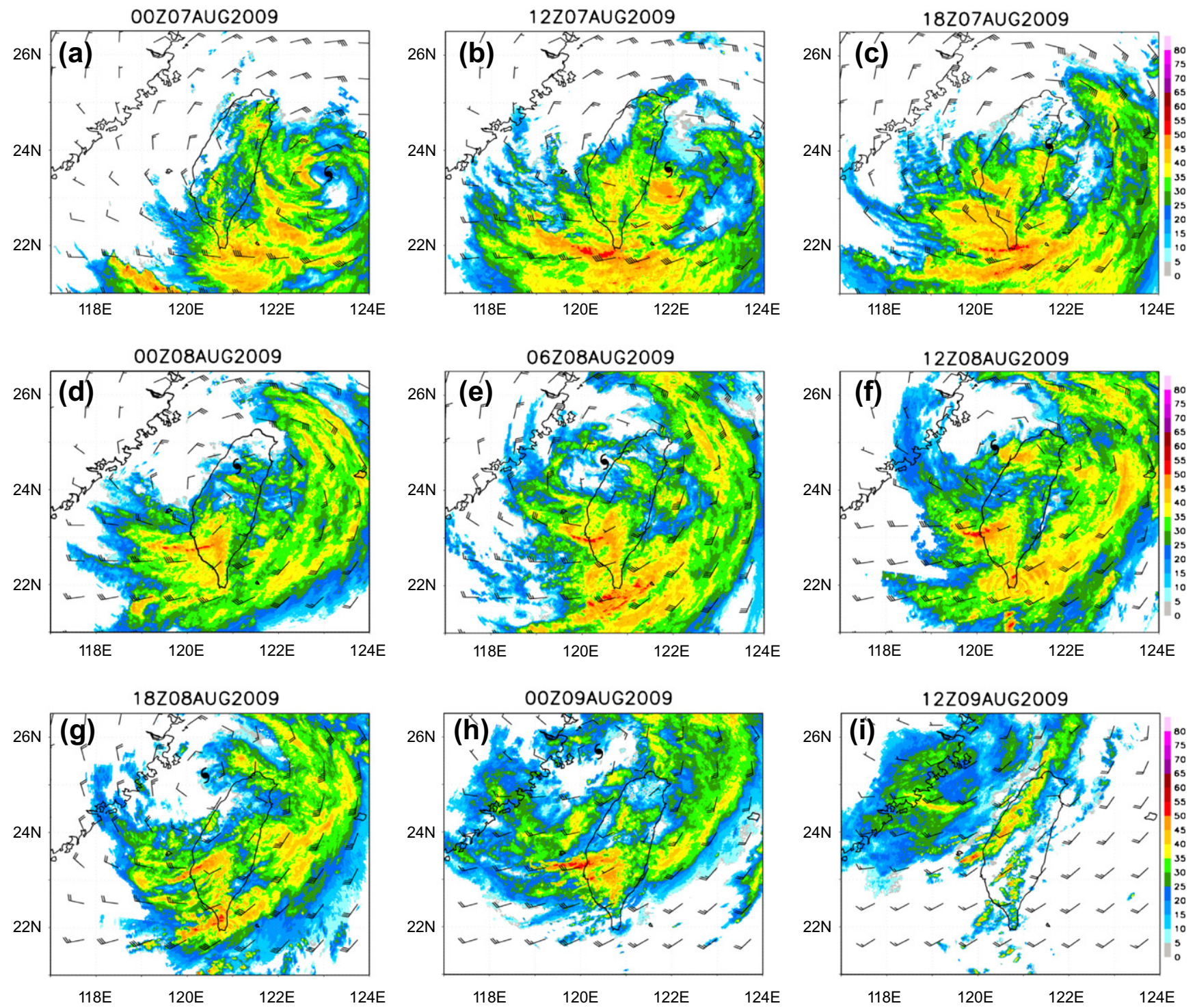

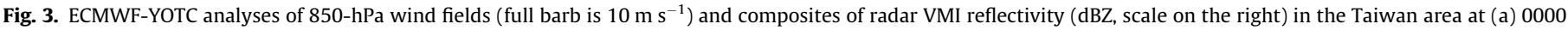
UTC 7 August, every 6 h from (b) 1200 UTC 7 to (h) 0000 UTC 9 August, and at (i) 1200 UTC 9 August 2009. The JTWC center of Morakot is depicted by TY symbols.

rapidly from over $450 \mathrm{~mm}$ on 6 August (not shown) to roughly $1000 \mathrm{~mm}$ on 7 August (Fig. 4a), and further to $1500 \mathrm{~mm}$ on $8 \mathrm{Au}-$ gust (Fig. 4b; cf. Figs. 3a-d of Huang et al., 2011, and Fig. 1b of Fang et al., 2011). Even on 9 August as the TC gradually moved away (cf. Fig. 1), the peak daily rainfall still reached $700 \mathrm{~mm}$ (Fig. 4c).

While flash floods in many regions around the world are often caused by a few hundred millimeters of precipitation, the 4-day rainfall accumulation reached an unprecedented $2855 \mathrm{~mm}$ (Fig. 4d). For the region with most rain (i.e., southern CMR, depicted by the dotted box), large rainrates (average $\geqslant 20 \mathrm{~mm} \mathrm{~h}^{-1}$ ) occurred almost continuously from about 1800 UTC 7 to 0600 UTC 9 August (Fig. 5). Moreover, the rainrates exceeded $40 \mathrm{~mm} \mathrm{~h}^{-1}$ over 0600-1800 UTC 8 August during the post-landfall period when Morakot was moving at only $5 \mathrm{~km} \mathrm{~h}^{-1}$, as also indicated by Wang et al. (2012). At around 2200 UTC 8 August, the Shiao-lin Village was tragically buried and nearly 660 perished (Fig. 5, cf. Fig. 4d for location).

At real time prior to the event of Morakot in 2009, the above-mentioned extreme rainfall was not adequately predicted by operational models. For example, Wu et al. (2010) show three experiments by the Weather Research and Forecasting (WRF) model using different advection schemes starting at 0000 UTC 6 August, with a 4-day (6-9 August) maximum rainfall between 1084 and $1365 \mathrm{~mm}$ (their Figs. 16-18 and Table 3). These values account for only about $38-48 \%$ of the observed magnitude (cf. Fig. 4d). The real-time forecast by the Naval Research Laboratory's Coupled Ocean/Atmosphere Mesoscale Prediction System for Tropical Cyclones (COAMPS-TC) at 1200 UTC 6 August suffered a similar under-prediction in rainfall due partly to a faster translation speed during and after landfall (Hendricks et al., 2011, their Fig. 5 and Table 1). The official maximum rainfall forecasts issued by the Central Weather Bureau (CWB) of Taiwan prior and leading to the event, likewise, also showed deficiency in total amount (Yeh et al., 2010), which will be further discussed in Section 5.

Thus, while many previous studies seek physical explanations for Typhoon Morakot (2009), the focus in this study is rainfall simulation and particularly prediction of this event from the perspectives of real-time operation and hydrological applications. The specific scientific questions include: (1) Can the extreme rainfall brought by Morakot be better predicted in advance? (2) If yes, how long is the lead-time? (3) How can the prediction be further improved, and (4) what are the best possible scenario (for rainfall 

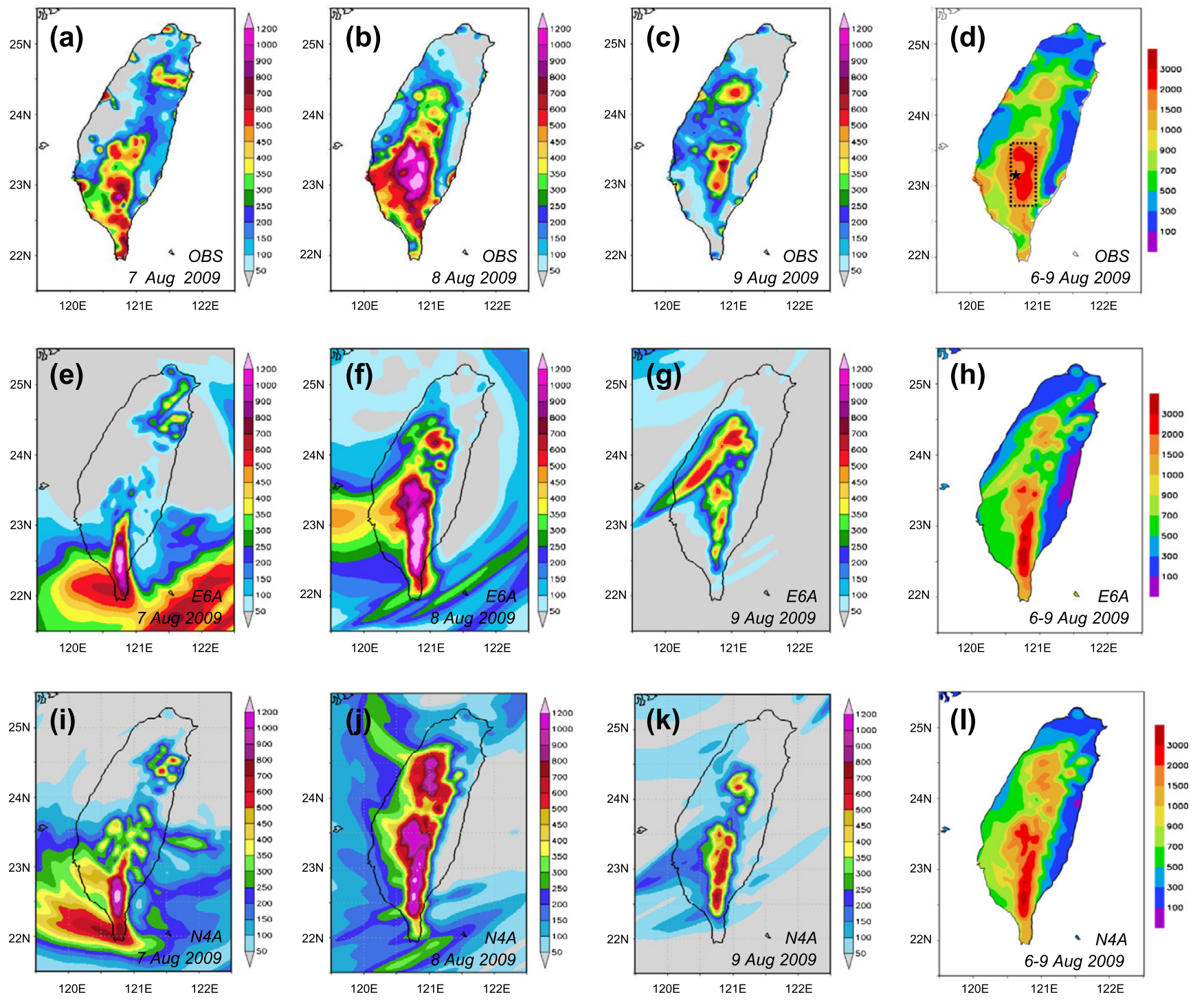

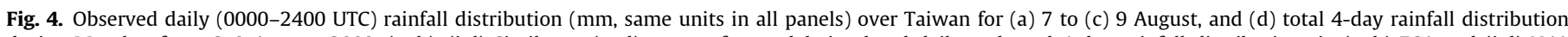

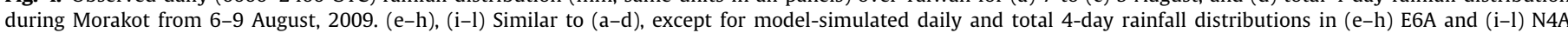

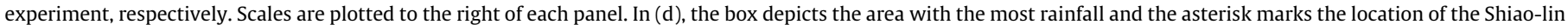
Village $\left(23.16^{\circ} \mathrm{N}, 120.64^{\circ} \mathrm{E}\right)$.

prediction and lead-time) without errors in global model forecasts? While the final question may be hypothetical, it can help us understand the potential lead-time achievable in future typhoon events. Although it remains a highly challenging task to accurately predict heavy precipitation at specific locations and time periods for high-impact weathers such as Typhoon Morakot (e.g., Hendricks et al., 2011; Fang et al., 2011), rainfall predictions are essential for hazard prevention/reduction and emergency management. Rainfall data also serve as inputs to run-off models, and thus the prediction of those areas under threats of floods/mudslides are directly affected by the accuracy of the rainfall prediction. A state-of-the-art, high-resolution cloud model called the Cloud-Resolving Storm Simulator (CReSS) will be used for quantitative precipitation forecasts (QPFs) of TY Morakot and address the scientific questions stated above. It will be shown that this type of model can realistically reproduce the event with high accuracy and fidelity, including the rainfall distribution and timing over Taiwan. In addition, when properly configured, high-quality rainfall forecasts by the CReSS model would have provided in real time very useful information roughly 2 days prior to the heaviest rainfall in this event. Such predictions would provide additional time for reaction when it matters the most, and thus may significantly reduce casualties and property losses.

The remainder of this paper is arranged as follows. In Sections 2 and 3, the data and analysis methods as well as the CReSS model and the experiments used in this study are described. The model simulations, real-time forecasts, and hindcasts and the QPF performance are discussed in Section 4. In Sections 5 and 6, further discussion and the conclusion are given, respectively.

\section{Data and methodology}

\subsection{Data}

The observations used to describe Morakot (2009) and to validate model results include: weather maps at standard levels; best-track and basic TC information from JTWC; hourly VMI reflectivity composites from radars in Taiwan; and hourly data from a network of over 400 gauges of the Automatic Rainfall and 


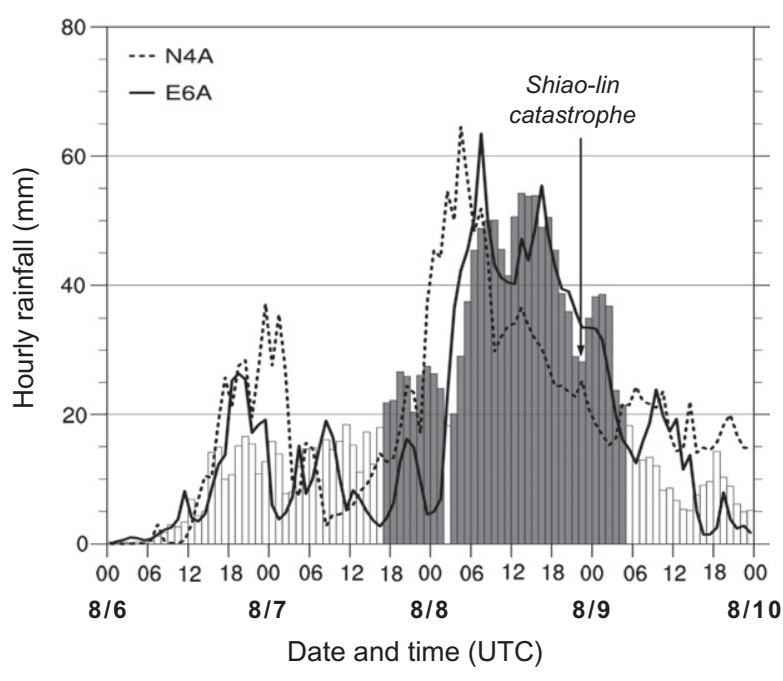

Fig. 5. Observed (bars, gray shaded for $\geqslant 20 \mathrm{~mm} \mathrm{~h}^{-1}$ ) and model-simulated histograms of hourly rainfall in E6A (thick solid line) and N4A (thick dashed line, all in $\mathrm{mm} \mathrm{h}^{-1}$ ) averaged inside the box in Fig. 4d through the 4-day period starting from 0000 UTC 6 August 2009. The time of Shiao-lin catastrophe is marked.

Meteorological Telemetry System (ARMTS; Hsu, 1998; Fig. 2). Some of these various observations have already been presented in Section 1 (Figs. 1, 3, 4a-d, and 5).

Two operational gridded analyses over the globe are used to provide initial and boundary conditions (IC/BCs) for the model simulations. The first is the special high-resolution analyses from the European Center for Medium-range Weather Forecasts (ECMWF) Year of Coordinated Observing Modeling and Forecasting Tropical Convection (YOTC) project (e.g., Waliser and Moncrieff, 2007; Moncrieff, 2010) that are available on a $0.25^{\circ}$ latitude/longitude grid at 20 pressure $(p)$ levels and 6-h intervals (0000, 0600, 1200, and 1800 UTC). The second set is the National Centers for Environmental Prediction (NCEP) final analyses at $1^{\circ} \times 1^{\circ}$ resolution at 26 levels that are also available every $6 \mathrm{~h}$. These datasets provide the IC/BCs of the CReSS model to be described later (Section 3.1). Besides meteorological analyses, terrain data on a 30 -s or $(1 / 120)^{\circ}$ grid, as well as weekly sea-surface temperature (SST, Reynolds et al., 2002) or NCEP analyzed SSTs (both at $1^{\circ} \times 1^{\circ}$ resolution) are also provided at the lower boundary of the model.

At the time of Morakot, the CReSS model was being integrated to $48 \mathrm{~h}$ at real time in a quasi-operational mode at 0000 and 1200 UTC (twice daily). For these integrations, the NCEP Global Forecasting System (GFS) analyses and forecasts were used as IC/ BCs. These real-time analyses differ slightly from the GFS final analyses in that a small fraction of the observations have not been received before the cut-off time. The GFS forecasts at 3-h intervals are used as BCs for the CReSS model, and thus introduce forecast errors which typically increase with time (i.e., forecast range). For more detailed information on how the analyses and forecasts are produced at NCEP, readers are referred to Kanamitsu (1989), Kalnay et al. (1990), Moorthi et al. (2001), Charles and Colle (2009), and Kleist et al. (2009).

To further investigate on the predictability of Typhoon Morakot, hindcast experiments using the CReSS model are also made to 6 days ( $144 \mathrm{~h}$ ) using a larger domain. For these runs with a longer forecast range, the NCEP final analyses and GFS forecasts at 12-h intervals were used for ICs and BCs, respectively.

\subsection{Analysis methods}

Each of the CReSS model integrations is compared with observations for the TC track and the accumulative rainfall distributions in Taiwan over various time periods. In addition to subjective verifications of model performance, several objective skill scores commonly used to evaluate model QPFs will be presented: threat score (TS); bias score (BS); probability of detection (POD); and falsealarm rate (FAR; Mesinger and Black, 1992; Wilks, 1995; Hong, 2003). These skill scores are defined as

$\mathrm{TS}=\mathrm{H} /(\mathrm{O}+\mathrm{F}-\mathrm{H})$,

$\mathrm{BS}=\mathrm{F} / \mathrm{O}$

$\mathrm{POD}=\mathrm{H} / \mathrm{O}$,

$\mathrm{FAR}=(\mathrm{F}-\mathrm{H}) / \mathrm{F}=1-\mathrm{H} / \mathrm{F}$.

where $\mathrm{O}, \mathrm{F}, \mathrm{H}$, and $\mathrm{N}$ represent the observed and model-predicted areas of rainfall exceeding a given threshold value, their intersection, and the entire region of verification, respectively, as illustrated in Fig. 6. Thus, TS, POD, and FAR all have values between 0 and 1, and a higher (lower) value for TS and POD (FAR) represents a better performance. The BS is a ratio of the relative sizes of the rain areas in the forecast and in the observations, and thus can vary from 0 to infinity (e.g., Wilks, 1995), but the ideal value is 1 . A range of thresholds from 0.05 to $1000 \mathrm{~mm}$ per $24 \mathrm{~h}$ are used to compute the skill scores, and the model-produced rainfall patterns over Taiwan in various simulations, forecasts, and hindcasts are evaluated against the observations. Model rainfall values at grid points are bi-linearly interpolated to rain-gauge sites, and then the skill scores for various thresholds are computed for all available sites. Although the gauges are not evenly distributed (cf. Fig. 2), the sites are given equal weights.

\section{The CReSS model and experiments}

\subsection{Description of the CReSS model}

The CReSS model (versions 2.2 and 2.3) is a non-hydrostatic, fully compressible, cloud-resolving model developed at the Hydrospheric Atmospheric Research Center of Nagoya University, Japan (Tsuboki and Sakakibara, 2002, 2007). This cloud model employs a terrain-following vertical coordinate, with prognostic equations for 3-D momentum $(u, v, w), p$, potential temperature $(\Theta)$, and mixing ratios of water vapor $\left(q_{v}\right)$ and other hydrometeors $\left(q_{x}\right.$, where $x$ denotes a species). To properly simulate clouds at high resolution, an explicit bulk cold rain scheme based on Lin et al. (1983), Cotton et al. (1986), Murakami (1990), Ikawa and Saito (1991), and Murakami et al. (1994) are used with no cumulus parameterization. A total of six species (water vapor, cloud water,

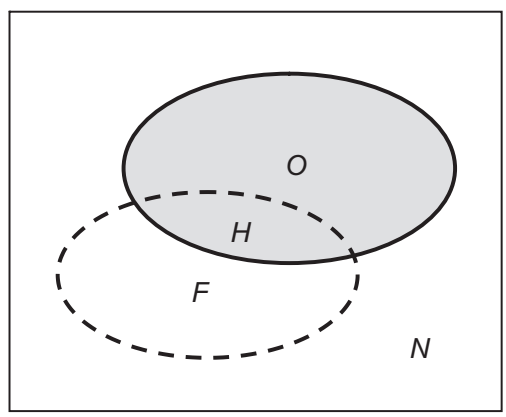

Fig. 6. Schematic of the verification of model QPF at a specified threshold for a given time period in an area. The observed rainfall area exceeding the threshold is labeled "O", the model forecast area is "F", and their intersection is " $H$ " (i.e., the hit area). The entire verification domain is denoted by "N". The area of $\mathrm{O}-\mathrm{H}$ is misses (occurred but not predicted), $\mathrm{F}-\mathrm{H}$ is false alarm (predicted but not happened), and $\mathrm{N}-(\mathrm{F}+\mathrm{O}-\mathrm{H})$ is correct negatives (correctly predicted to not occur). 
cloud ice, rain, snow, and graupel) are included with microphysical processes of nucleation (condensation), sublimation, evaporation, deposition, freezing, melting, falling, conversion, collection, aggregation, and liquid shedding (Tsuboki and Sakakibara, 2002). Sub-grid scale turbulent mixing is parameterized using 1.5-order closure with turbulent kinetic energy (TKE) prediction (Tsuboki and Sakakibara, 2007), and planetary boundary layer (PBL) processes are parameterized following Mellor and Yamada (1974) and Segami et al. (1989). Momentum and energy fluxes and radiation at the surface are also considered with a substrate model (Kondo, 1976; Louis et al., 1981; Segami et al., 1989) but cloud radiation is neglected. The main features of the CReSS model are summarized in Table 1 , and the readers are referred to Tsuboki and Sakakibara $(2002,2007)$ for a more complete description.

For computational efficiency, a time-splitting scheme (Klemp and Wilhelmson, 1978) is adopted in the CReSS model to separately integrate fast and slow waves using the filtered leap-frog method (Asselin, 1972) for large $(\Delta t)$ and the implicit Crank-Nicolson scheme for small time steps $(\Delta \tau)$ in the vertical (Table 1$)$. For large-scale parallel computing, data exchanges between individual processing elements (PEs) are performed by the Message Passing Interface (MPI) and/or Open MP. The CReSS model has been used to study various types of convective systems and TCs (e.g., Liu et al., 2004; Maesaka et al., 2006; Wang et al., 2005, 2009, 2011; Wang and Huang, 2009; Hattori et al., 2010).

\subsection{Model experiments}

As described earlier, three types of CReSS model experiments are performed in this study: simulation, real-time forecast, and hindcast. A total of eight runs will be described (Tables 1 and 2). Names of the experiments consist of three letters that indicate the type (E or N for simulation using ECMWF-YOTC or NCEP analyses, $\mathrm{F}$ for forecast, or $\mathrm{H}$ for hindcast), starting date (in August 2009), and initial time (A for 0000 and B for 1200 UTC) of the integration (Table 2). Limited by computational resources, the forecast runs in 2009 were on a smaller domain $(1088 \mathrm{~km} \times 960 \mathrm{~km}$, cf. Fig. 1) with a 4-km grid size and 40 levels (Table 2 ). The simulation and hindcast integrations were performed with a grid size of $3 \mathrm{~km}$ and more vertical layers on a larger domain (45 or 50 levels and at least $1728 \mathrm{~km} \times 1440 \mathrm{~km}$, also Tables 1 and 2). As mentioned in Section 2.1 , the hindcast runs also have a longer range $(144 \mathrm{~h})$ compared to forecast runs $(48 \mathrm{~h})$ and are used to explore how the forecasts for Morakot might be improved at real time, while both utilize NCEP GFS analyses as ICs and forecasts as BCs. In contrast, the simulation experiments employ only the analyses (from ECMWF or NCEP) as IC/BCs, and are used to validate the model and serve as a benchmark (see Section 4.1).

\section{Model results}

\subsection{Simulations using analyses}

First, results from the two CReSS model simulations in which analyses from ECMWF or NCEP are used as IC/BCs will be presented to validate the model. Such analyses are based on all available observations and are the best representations of the state of the atmosphere at each time for specification of the model BCs (every $6 \mathrm{~h}$ ). Hence, with relatively small uncertainties (from observation and analyses errors, model framework and physics, and numerical techniques, etc.), the CReSS model simulations using these analyses (as opposed to forecast fields) for BCs may be viewed as the best possible results achievable in the forecasting mode in practice and serve as a benchmark.

The 4-day simulation E6A starting from 0000 UTC 6 August and using the $0.25^{\circ}$ ECMWF-YOTC analyses as IC/BCs (Table 2) predicts the track of Morakot (2009) in close agreement with the positions in the analyses and in the JTWC best-track (Figs. 1 and 7). These predicted TC positions are determined from the low-level center (at roughly $850-700 \mathrm{hPa}$ ) using both pressure and wind fields. Model-simulated column maximum mixing ratio of total precipitating hydrometeors (rain, snow, plus graupel) and wind fields near $850 \mathrm{hPa}$ from the E6A simulation are presented in Fig. 8. This mixing ratio may be compared with the radar VMI reflectivity (i.e., precipitation echo intensity) in Fig. 3. The similarity in these two figures indicates that the CReSS model predicts well the persistent asymmetric rainfall structure of Morakot. Furthermore, the general locations of the $\mathrm{N}-\mathrm{S}$ orographic rainband along the southern CMR and the rainband with a nearly E-W alignment across southwestern Taiwan are also predicted by the model (Fig. 8c-h).

Table 1

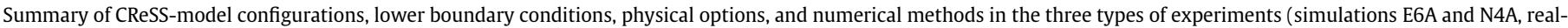
time forecast, and hindcast) in this study. The time integration schemes can be classified as horizontal explicit (HE), vertical explicit (VE), and vertical implicit (VI).

\begin{tabular}{|c|c|c|c|}
\hline & Simulation E6A & Real-time forecast & Simulation N4A and hindcast \\
\hline \multicolumn{4}{|l|}{ Domain setup and resolution } \\
\hline Model version & v.2.3 & v.2.2 & v.2.3 \\
\hline Projection & \multicolumn{3}{|c|}{ Lambert conformal, center at $120^{\circ} \mathrm{E}$, secant at $10^{\circ} \mathrm{N}$ and $40^{\circ} \mathrm{N}$} \\
\hline Horizontal grid size & $3 \mathrm{~km}$ & $4 \mathrm{~km}$ & $3 \mathrm{~km}$ \\
\hline Vertical grid size $(\Delta z)$ & $100-745 \mathrm{~m}^{\mathrm{a}}$ & $200-663 \mathrm{~m}^{\mathrm{a}}$ & $100-937 \mathrm{~m}^{\mathrm{a}}$ \\
\hline Averaged $\Delta z$ and levels & $500 \mathrm{~m}, 50$ levels & $500 \mathrm{~m}, 40$ levels & $667 \mathrm{~m}, 45$ levels \\
\hline Model top & $25 \mathrm{~km}$ & $20 \mathrm{~km}$ & $30 \mathrm{~km}$ \\
\hline \multicolumn{4}{|l|}{ Lower boundary conditions } \\
\hline SST & Weekly mean $\left(1^{\circ}\right)$ & NCEP analysis $\left(1^{\circ}\right)$ & NCEP analysis $\left(1^{\circ}\right)$ \\
\hline Topography & \multicolumn{3}{|c|}{ Digital terrain elevation data at $(1 / 120)^{\circ}$ resolution } \\
\hline \multicolumn{4}{|l|}{ Model physics } \\
\hline Advection and diffusion & \multicolumn{3}{|c|}{ Both fourth-order in horizontal and vertical } \\
\hline Cloud microphysics & \multicolumn{3}{|c|}{ Bulk cold rain scheme (6 species) } \\
\hline Cumulus parameterization & \multicolumn{3}{|c|}{ None } \\
\hline PBL parameterization & \multicolumn{3}{|c|}{ 1.5-Order closure with TKE prediction } \\
\hline Surface processes & \multicolumn{3}{|c|}{ Energy and momentum fluxes, shortwave and longwave radiation } \\
\hline Soil model & \multicolumn{3}{|c|}{41 Levels, every $5 \mathrm{~cm}$ to $2 \mathrm{~m}$ deep } \\
\hline \multicolumn{4}{|l|}{ Numerical methods } \\
\hline Time steps $(\Delta t, \Delta \tau)$ & $5.0 \mathrm{~s}, 2.5 \mathrm{~s}$ & $6.0 \mathrm{~s}, 3.0 \mathrm{~s}$ & $4.0 \mathrm{~s}, 2.0 \mathrm{~s}$ \\
\hline Time integration & \multicolumn{3}{|c|}{ Filtered leapfrog for $\Delta t$ (HE-VE), leapfrog and Crank-Nicolson for $\Delta \tau$ (HE-VI) } \\
\hline
\end{tabular}

a The vertical grid spacing $(\Delta z)$ of CReSS is stretched, with smallest spacing at the bottom and larger spacing toward the model top. 
Table 2

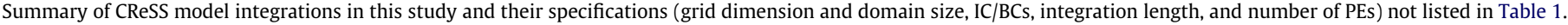

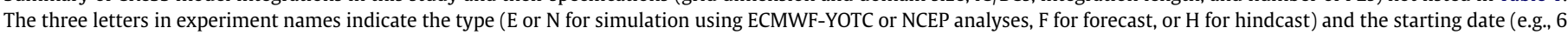
for 6 August 2009) and time (A for 0000 UTC and B for 1200 UTC) of the integration.

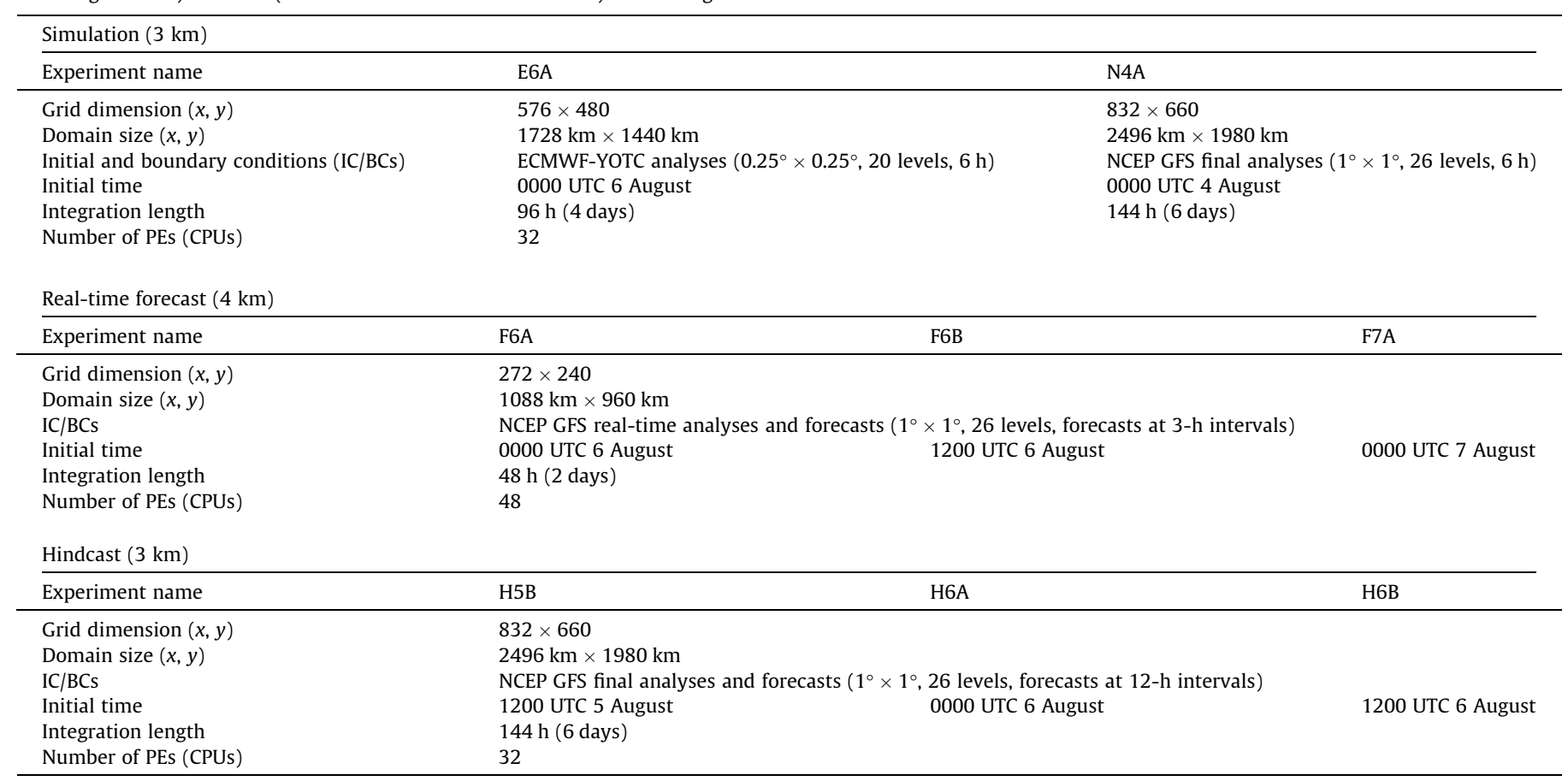

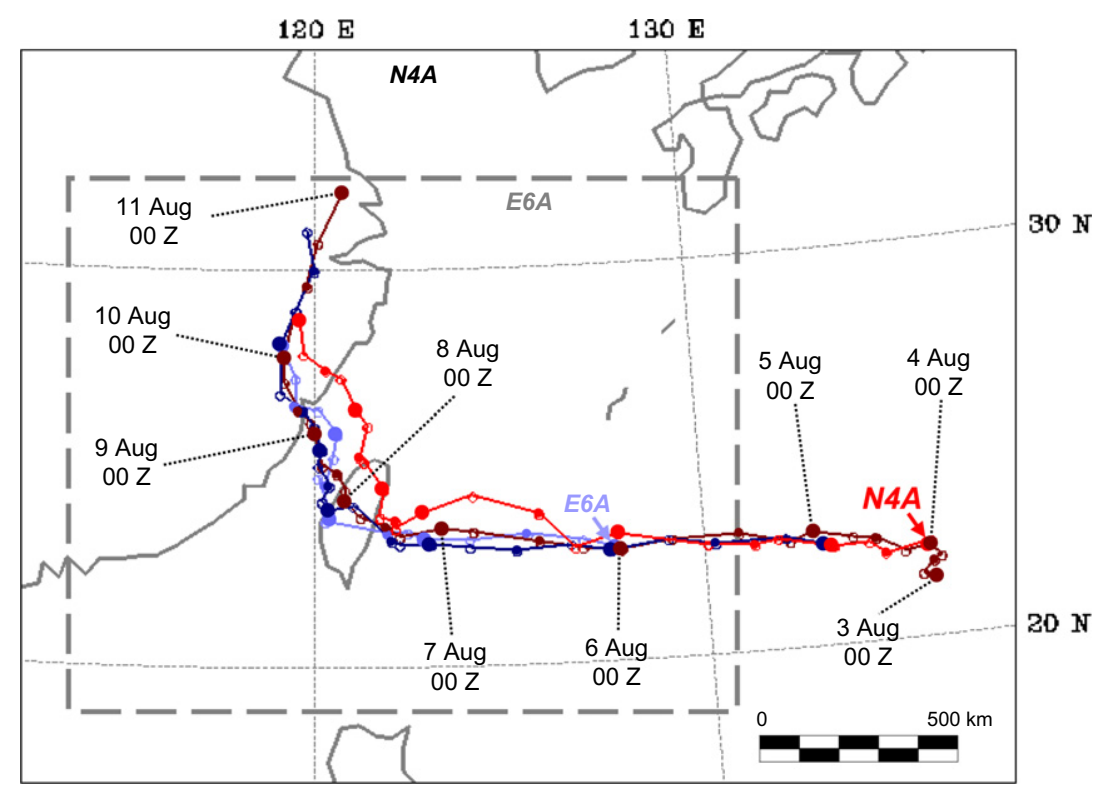

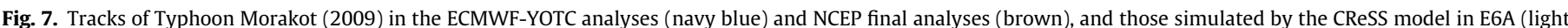

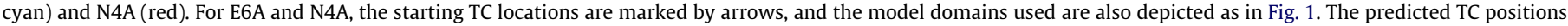
are marked each $6 \mathrm{~h}$ by open circles, solid circles (at 1200 UTC), and enlarged solid circles (at 0000 UTC, also labeled for the NCEP analyzed track).

Due to the successful simulation of both the slow TC motion on 7-8 August and the associated rainbands (Figs. 7 and 8 ), the predicted daily (7-9 August) and total rainfall distributions in E6A (Figs. $4 \mathrm{e}-\mathrm{h}$ ) also compare favorably with the observations in both pattern and amount (cf. Figs. 4a-d). In E6A, the 4-day total rainfall (6-9 August) maximum over southern CMR is over $3000 \mathrm{~mm}$ and even exceeds the observations (Fig. $4 \mathrm{~d}$ and $\mathrm{h}$ ). In both the prediction and observation, the daily rainfall is the most on 8 August, and the two distributions also agree quite well (Fig. 4b and f). The model appears to over-predict the rainfall along the ridge of southern CMR (south of about $22.7^{\circ} \mathrm{N}$ ). However, since very few rain-gauges exist in this remote area for verification (cf. Fig. 2), whether this tendency is true requires further study, as noted in Wang et al. (2012). Over the southwestern plain, the simulation E6A predicts a total rainfall of near $700 \mathrm{~mm}$, somewhat lower than the observed amount (Fig. 4d and h). For central Taiwan, the model also shows some under-estimate in rainfall on 7 August and some over-estimate on 9 August.

The evolution of the hourly rainfall averaged over the same rectangular area in CMR (cf. Fig. 4d) as simulated in E6A matches 

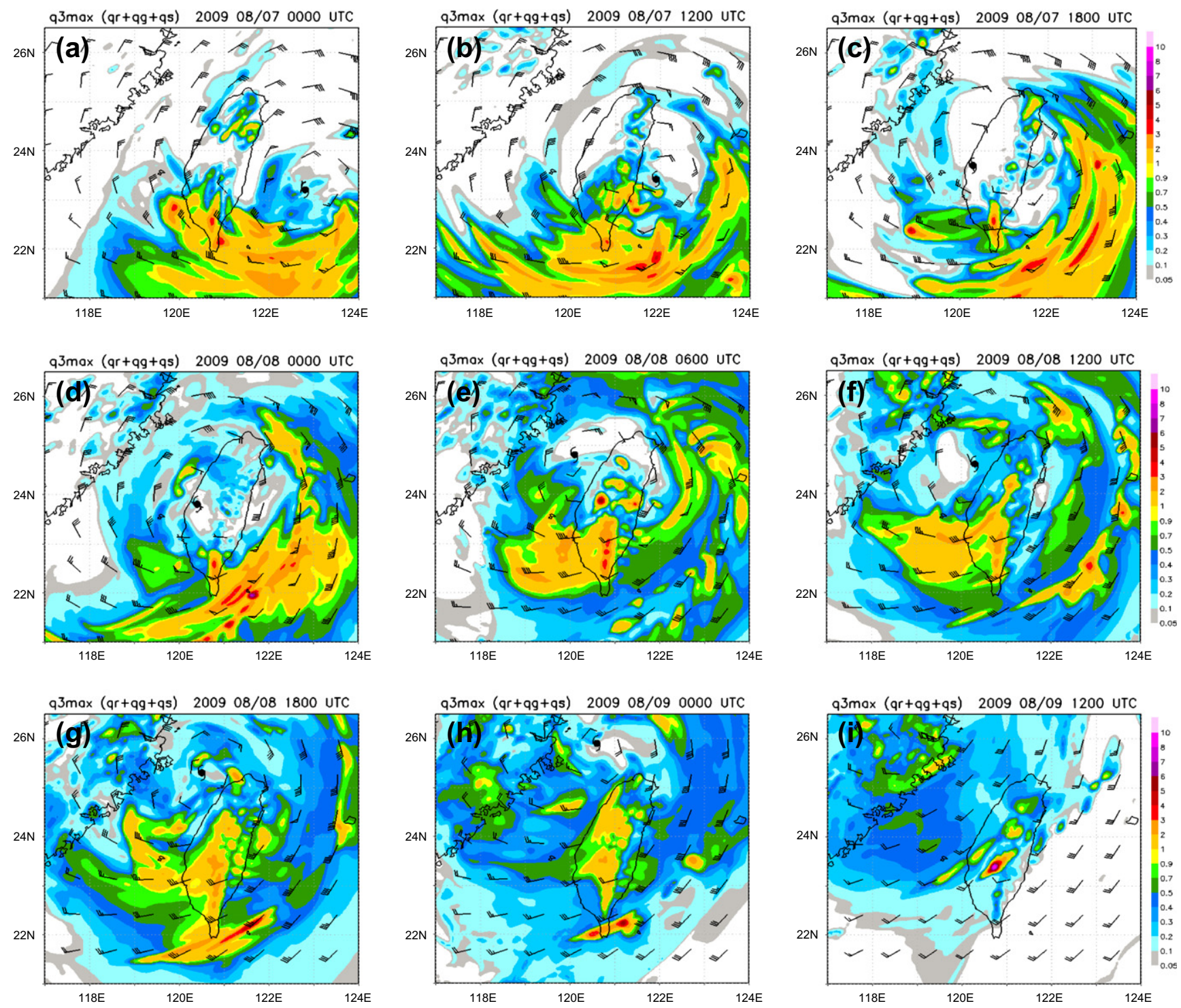

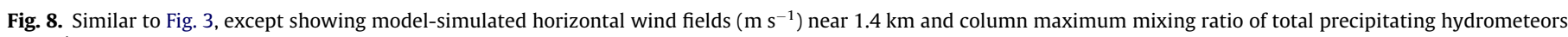
$\left(\mathrm{g} \mathrm{kg}^{-1}\right.$, rain + snow + graupel $)$ in the E6A simulation. The predicted centers of Morakot in E6A are depicted by the TY symbols.

the observations quite closely (Fig. 5), with the largest rainrates also on 8 August. In addition, the predicted torrential rainrates do not decrease until the TC center moves about $350 \mathrm{~km}$ from the southern CMR (Figs. 5 and 7). Such a highly realistic rainfall simulation could not have been achieved without a successful reproduction of the storm track, including the slow motion of the TC during the post-landfall period on 8 August (cf. Figs. 1 and 7). Nevertheless, it should be noted that the model in the E6A run underestimates the rainfall in southern CMR to some extent on 7 August (Fig. 5; cf. Fig. 4a and e). A more detailed description of the E6A simulation can be found in Wang et al. (2012, their experiment CTL1), who relate the simulated rainfall distribution of Morakot to the track evolution.

The skill scores, including TS, BS, POD, and FAR, of the 24-h daily rainfall simulated in E6A are shown in Fig. 9 for a range of rainfall thresholds from 0.05 to $1000 \mathrm{~mm}$. From the perspective of hydrological hazards caused by extreme rainfall, more emphasis is placed on model performance for the middle-to-high rainfall thresholds and on the dates with the most rain, i.e., 7-8 August. The TS and POD values (Fig. 9a and c) typically decrease with increasing threshold as the sizes of the rain areas (i.e., O, F, and likely also $\mathrm{H}$ in Fig. 6) become smaller. For the same 24-h period, the two curves are very similar with POD $\geqslant$ TS (sometimes only slightly), since $\mathrm{F}-\mathrm{H}$ is always $\geqslant 0$ [cf. Fig. 6 and Eqs. (1) and (3)], and thus provide similar information. The most significant feature is that both TS and POD are the highest on 8 August (48$72 \mathrm{~h}$ ), which suggests a better performance when there is more rain (Fig. 9a and c). As a consequence, the TS and POD values decrease very slowly from a perfect value of 1 at the $0.05 \mathrm{~mm}$ threshold, and remain above 0.7 for TS and 0.9 for POD up to the $250 \mathrm{~mm}$ threshold. At even higher thresholds of 500 and $1000 \mathrm{~mm}$, which are rarely used, the TS and POD values on 8 August were still about 0.4 and 0.3 , respectively (Fig. 9a). On other days when the TS and POD values decrease more rapidly, they are at least about 0.33 and 0.4 up to the $250 \mathrm{~mm}$ threshold.

In contrast to TS and POD, the FAR (Fig. 9d) generally increases with increasing thresholds. The FAR in E6A is also the smallest on 8 August (below about 0.3 across all thresholds), and remains below 0.6 up to the $250 \mathrm{~mm}$ threshold on other days. In terms of the BS (Fig. 9b), the values for 8 August are also the most satisfactory in that they are very close to 1 until above the $250 \mathrm{~mm}$ threshold. At larger thresholds, some underproduction occurs in the model 


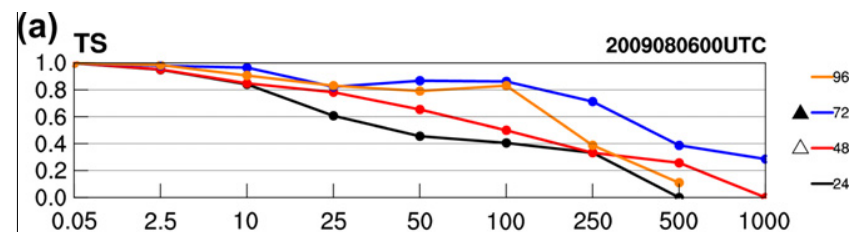

(b) ${ }_{\text {BS }}$
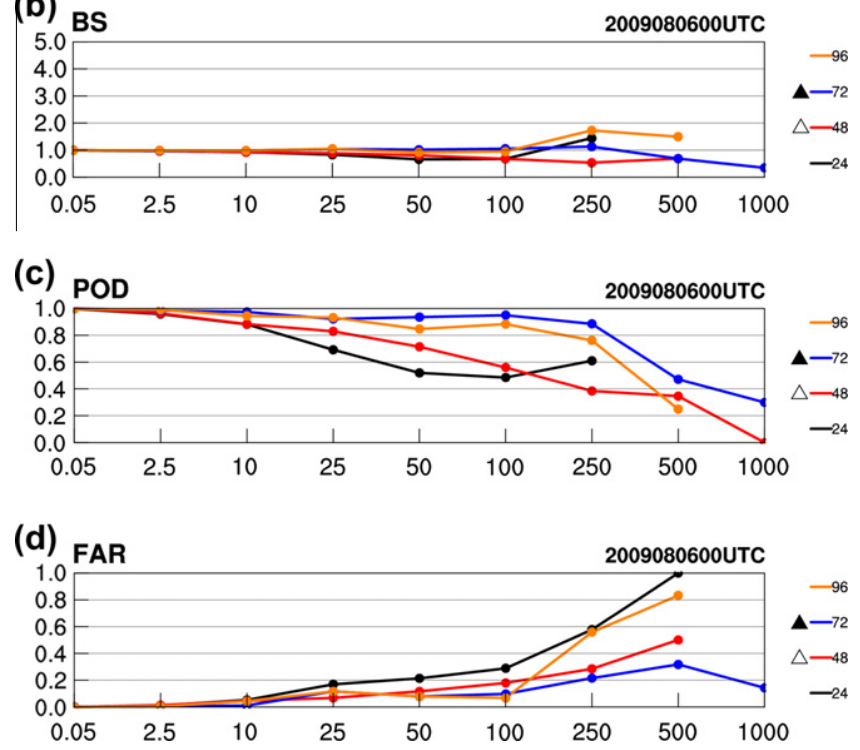

Fig. 9. Skill scores, including (a) TS, (b) BS, (c) POD, and (d) FAR of simulated 24-h rainfall amounts [see colored line definition on right for the ending times (hours into simulation) of the 24-h periods] by CReSS in E6A starting from 0000 UTC 6 August $(96 \mathrm{~h}$ ) as a function of rainfall thresholds ( $\mathrm{mm}$ ). The 24-h period with the highest (second highest) rainfall is marked by a solid (open) triangle.

compared to rain-gauges sites, confirming the lack of actual observations for QPF verification over the remote area of southern CMR as discussed earlier (cf. Fig. $4 \mathrm{~b}$ and f). Similar conditions of $\mathrm{BS}<1$ also exist over the range of $25-100 \mathrm{~mm}$ on 6 August $(0-24 \mathrm{~h})$ and $25-250 \mathrm{~mm}$ on 7 August $(24-48 \mathrm{~h}$ ) in E6A, which causes TS and POD to decrease more rapidly (Fig. 9a-c). Only on 9 August (72-96 h) there is some overproduction in rainfall predicted at 250-500 mm, which also leads to a decrease in TS (and an increase in FAR). Though not serious, the above discrepancies as revealed by the BS scores are in agreement with earlier discussion.

Overall, the skill scores in Fig. 9 are considered to be very satisfactory model predictions of daily rainfall, especially on 8 August, and are consistent with subjective comparisons in Fig. 4a-h and 5 . The TS values $(\geqslant 0.8,0.7,0.4$, and 0.3 for thresholds of $0.05-$ $100,250,500$, and $1000 \mathrm{~mm}$ ) are strikingly high compared to other studies of warm-season rainfall associated with TCs or otherwise in other regions and near Taiwan (e.g., Fritsch and Carbone, 2004; Huang et al., 2005; Nagarajan et al., 2006; Tuleya et al., 2007). Such high skill scores apparently result from two main causes: (1) A phase-locking mechanism of rainfall to Taiwan topography under TC influence as reviewed in Section 1 (and cf. Figs. 2, 3, and 4ad); and (2) a relatively high chance of rainfall amounts exceeding the lower thresholds at verification points in this case, as all rain-gauge sites are confined to the island (i.e., $\mathrm{F}$ and $\mathrm{O}$ tend to approach $\mathrm{N}$ in Fig. 6, also cf. Fig. 2). From Fig. 9, it is also evident that the performance of the model as measured by the TS (or other similar scores) over the middle-to-high threshold range (roughly $>25 \mathrm{~mm}$ ) can vary substantially from 1 day to the next during the integration. Using mean scores from multiple runs over a time period that includes days with less rainfall (or rainfall not linked to the TC) may not be appropriate from the standpoint of hazard prevention/reduction, because the model performance may be obscured at key times just prior to the occurrence of the heavy rainfalls.

In the N4A experiment that uses the NCEP $1^{\circ} \times 1^{\circ}$ final analyses as IC/BCs and an enlarged model domain $(2496 \mathrm{~km} \times 1980 \mathrm{~km}$, Table 2), the $3-\mathrm{km}$ CReSS simulation started 2 days earlier (at 0000 UTC 4 August 2009) also reproduces a track fairly close to the NCEP track and the JTWC best-track (Figs. 1 and 7). Hence, the daily and total rainfall amounts over Taiwan in N4A (Fig. 4i-1) are quite similar to those in E6A and observations (Fig. 4a-h), and so does the hourly rainfall evolution over southern CMR (Fig. 5). Nonetheless, the 4-day total rainfall over the southwestern plain is increased and becomes closer to the observation in N4A (Fig. 4d, h, and 1 ) when a larger domain that extends farther to the southwest is used, despite a more coarse resolution in the IC/BCs. In N4A, the TS values (not shown) are low $(\leqslant 0.25)$ for 4 and 5 August $(0-$ $48 \mathrm{~h}$ ) when localized rainfall $(>50-100 \mathrm{~mm}$ ) not directly linked to Morakot occurred in Taiwan. However, the TS then improves dramatically during $7-8$ August $(72-120 \mathrm{~h}$ ) with peak value of $\geqslant 0.7$, 0.55 , and 0.25 at thresholds of $0.05-100,250$, and $500 \mathrm{~mm}$, only slightly lower than those of E6A (cf. Fig. 9a). Apparently based on only 1 or 2 sites, the TS at the highest threshold of $1000 \mathrm{~mm}$ was a perfect 1.0 on day 4 (72-96 h, 7 August, not shown). Thus, more emphasis should be on the middle-to-high rainfall thresholds, because the highest threshold (if reasonably close to the maximum) may not be representative due to the small size of rain area (or the limited number of sites reaching the criterion).

It is noteworthy that similar results have been obtained from an integration begun 2 days earlier in N4A compared to E6A, which is attributed to the TC track error remaining small (Table 3 ). In this case, the higher resolution of the ECMWF-YOTC analyses was not essential, as the TC was far enough from Taiwan during early stages of the integration. For additional comparison, the N6A simulation (starting at 0000 UTC 6 August using NCEP analyses as IC/BCs) produces a 4-day rainfall distribution very similar to that in N4A, and thus more rain over the southwestern plains (not shown) compared to E6A. The N3A run resembles the N4A run in track and rainfall (not shown), and extends the lead-time by one more day, to about 5 days. Therefore, all simulation experiments discussed in this subsection yield comparable results, regardless which

Table 3

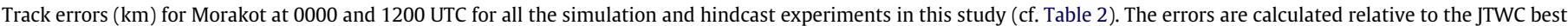
track, and are given up to 1200 UTC 9 August 2009. Entries greater than $200 \mathrm{~km}$ are indicated in boldface.

\begin{tabular}{|c|c|c|c|c|c|c|c|c|c|c|c|c|}
\hline \multirow{2}{*}{$\begin{array}{l}\text { Date in August } \\
\text { Time (UTC) }\end{array}$} & \multicolumn{2}{|l|}{4} & \multicolumn{2}{|l|}{5} & \multicolumn{2}{|l|}{6} & \multicolumn{2}{|l|}{7} & \multicolumn{2}{|l|}{8} & \multicolumn{2}{|l|}{9} \\
\hline & 0000 & 1200 & 0000 & 1200 & 0000 & 1200 & 0000 & 1200 & 0000 & 1200 & 0000 & 1200 \\
\hline \multicolumn{13}{|l|}{ Exp. } \\
\hline E6A & - & - & - & - & 36 & 22 & 42 & 20 & 99 & 32 & 28 & 22 \\
\hline N4A & 64 & 20 & 22 & 58 & 22 & 64 & 50 & 22 & 70 & 89 & 106 & 100 \\
\hline H5B & - & - & - & 10 & 22 & 64 & 128 & 214 & 455 & 696 & 550 & 632 \\
\hline H6A & - & - & - & - & 32 & 0 & 41 & 99 & 135 & 379 & 579 & 592 \\
\hline H6B & - & - & - & - & - & 10 & 50 & 78 & 114 & 156 & 318 & 291 \\
\hline
\end{tabular}




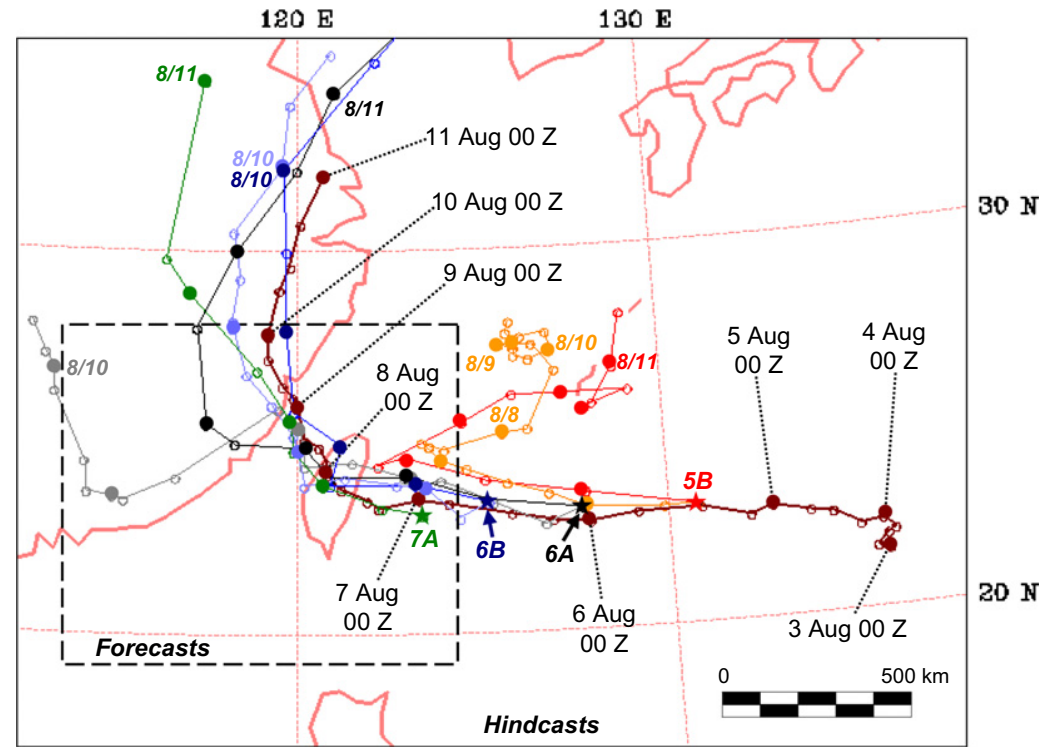

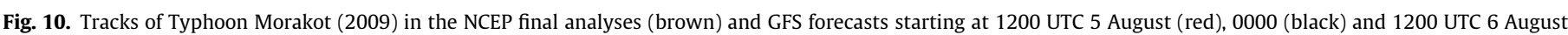

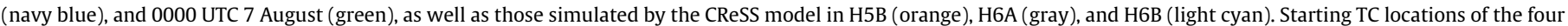

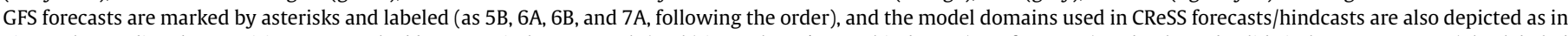

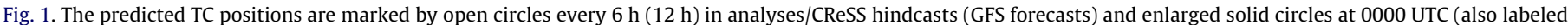
for the NCEP analyzed track at each day and near the end of each track).

dataset are used. It is also noted that similar, highly realistic simulations in rainfall can also be obtained using gridded analyses as IC/ BCs by other models such as the WRF model, starting from 0000 UTC 6 or 7 August (e.g., Nguyen and Chen, 2011; Fang et al., 2011; Huang et al., 2011; Tao et al., 2011).

\subsection{Real-time forecasts using small domain}

As mentioned in Section 2.1, another version of the CReSS model was being integrated at real time when Morakot occurred in 2009. Two 48-h integrations were being made daily at 0000 and 1200 UTC using NCEP GFS analyses/forecasts as IC/BCs (Table 1). In this section, three real-time forecasts during 0000 UTC 6-7 August (labeled F6A, F6B, and F7A) are shown to demonstrate what the CReSS model was capable of producing at real time with forecasting errors in the NCEP GFS and only limited computational resources (48 PEs, Table 2). Because the domain was rather small, the storm tracks in these real-time CReSS forecasts closely followed those in the GFS forecasts (Fig. 10) and thus not explicitly shown. For the forecast started at 0000 UTC 6 August (F6A), the TC is predicted to make landfall in Taiwan during 0800-1800 UTC 7 August and then move westward to a second landfall on mainland China around 0900 UTC 8 August, which is about 9-21 h too early (cf. Figs. 1 and 7). As a consequence, the F6A daily rainfall amounts on 6 and 7 August exceed 650 and $1300 \mathrm{~mm}$, respectively (Fig. 11a and b), and the 2-day total rainfall maximum is over $1900 \mathrm{~mm}$ (Fig. 11c). Even though the TC in the F6A forecast moves too fast and the predicted rainfall over 6-7 August is higher than observed (Fig. 11d), the 2-day rainfall pattern in Fig. 11c resembles the observations during the Morakot event with a peak value already $2 / 3$ (or $67 \%$ ) of the full magnitude (cf. Fig. 4d), and thus can provide useful information about the potential hazards.

In the F6B forecast started $12 \mathrm{~h}$ later, the TC was predicted to move slower and make landfall in Taiwan during 0900-2400 UTC 7 August (cf. Fig. 10), and then move toward the northwest over the Taiwan Strait and make landfall in China around 1600 UTC 8 August. Although the timing for Taiwan landfall is still early by about $6-15 \mathrm{~h}$, the better TC track during the landfall and post-landfall periods leads to an improved rainfall prediction (Fig. 11e-h). The maximum rainfall in the southern CMR was about $1950 \mathrm{~mm}$ and substantially more rain $(>800 \mathrm{~mm})$ was also predicted over the southwestern plains as observed (Fig. 11g and $h$ ).

In the F7A forecast started from 0000 UTC 7 August when the TC center was only about $200 \mathrm{~km}$ east of Taiwan, a highly realistic rainfall distribution was predicted for 8 August and the 2-day total in the southern CMR had maximum rainfall near $2400 \mathrm{~mm}$ (Fig. 11i-k) and slightly exceeded the observation (about $2150 \mathrm{~mm}$, Fig. 111). This overall success is attributed to a track forecast that was close to the observed track (cf. Figs. 7 and 10, exact tracks not shown). In real-time operation, however, the value of these forecasts (especially F7A) must be assessed considering a shortened lead-time to when the heaviest rainfall in southern CMR began (no later than 0600 UTC 8 August 2009, cf. Fig. 5). In the F7A forecast, the smaller predicted 24 -h rainfall for day 1 ( 7 August) compared to F6B (Fig. 11e and i) is attributed to the coarse resolution of the NCEP analyses $\left(1^{\circ} \times 1^{\circ}\right)$ used as ICs. Wang et al. (2012) did not find a similar issue when the ECMWF-YOTC data are used for the integration starting at 0000 UTC 8 August 2009 (their experiment CTL2).

The 0-24 and 24-48 h TS and BS curves for the three real-time F6A, F6B, and F7A forecasts are shown in Fig. 12. A common feature in the F6A and F6B forecasts is that the TS values for thresholds below $50 \mathrm{~mm}$ at $24-48 \mathrm{~h}$ (day 2 ) are slightly lower than those for 0$24 \mathrm{~h}$ (day 1 ), but considerably higher above the threshold of $50 \mathrm{~mm}$ (Fig. 12a and c). This may be attributed to the larger 24-h rainfall amounts during day 2 (cf. Figs. $4 a$ and b, 11a, b, e and f). At thresholds of $100-250 \mathrm{~mm}$, the TS values in both forecasts are above 0.5 , which suggests good skill in predicting the increasing heavy rainfall brought by Morakot. The BS values from F6A indicate an over-forecast in rainfall toward the higher threshold of $250 \mathrm{~mm}$ in day 1 (6 August), but nearly ideal rain-area sizes across all thresholds in day 2 (7 August). A similar tendency of over-prediction in day 1 (and slight under-prediction in day 2) is also noted for the F6B forecast (Fig. 12b and d). These tendencies are clearly 

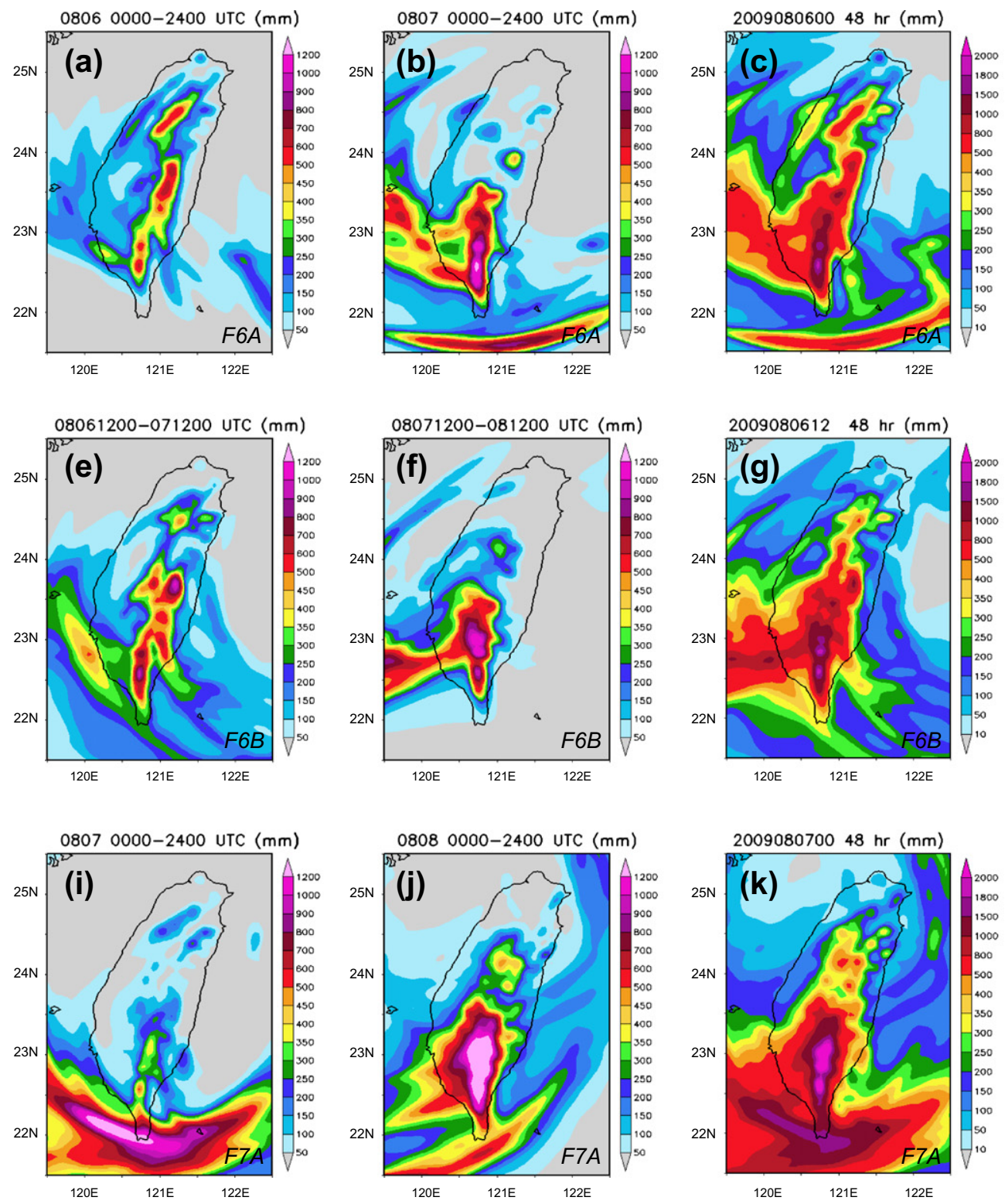
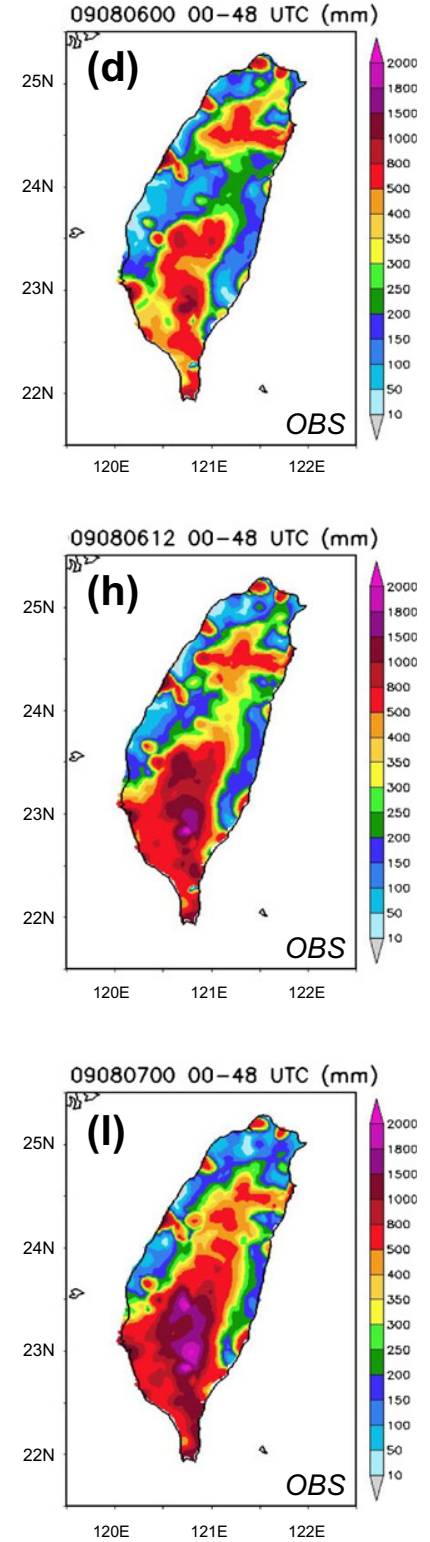

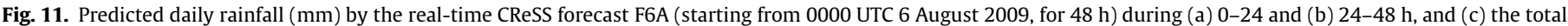

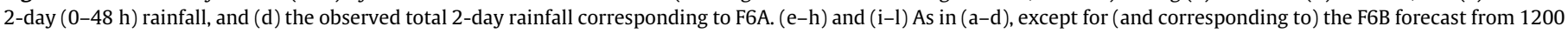
UTC 6 August and the F7A forecast from 0000 UTC 7 August, respectively. Scales are plotted to the right of each panel.

associated with the track error differences mentioned earlier (Fig. 10), and thus the CReSS model tends to predict too much rain on day 1 in both forecasts and not enough on day 2 in the F6B forecast.

The TS values for the F7A forecast (Fig. 12e) are consistently higher in day 2 (8 August) than day 1 (7 August), especially for the middle to high thresholds (50-1000 mm). The BS close to 1 at all thresholds (Fig. 12f) indicates the excellent F7A forecast of the rainfall on 8 August for the present case, albeit with a limited lead-time. It is particular noteworthy that the TS values for 8 August (24-48 h) are at least $0.8,0.5$, and 0.4 at thresholds of 0.05-250, 500 , and $1000 \mathrm{~mm}$ (Fig. 12e), which are even slightly higher than for the simulations E6A and N4A at high thresholds (cf. Fig. 9a).

\subsection{Hindcasts using large domain at longer range}

To further investigate on the predictability of Morakot, hindcasts were also made using a large domain $(2496 \mathrm{~km} \times 1980 \mathrm{~km}$, cf. Fig. 1) and a longer forecast interval up to $144 \mathrm{~h}$ (H5B to H6B in Table 2). Since the IC/BCs are from the GFS as in the real-time forecasts, these hindcasts illustrate the effects of a longer range, larger domain, and a slightly finer grid size compared to the realtime forecasts in Section 4.2 (Tables 1 and 2).

As shown in Fig. 10, the TC track predicted in H6A is quite close to that in the NCEP GFS, and landfall in Taiwan is predicted to occur during 1000-1600 UTC 7 August. Thus, the storm is still predicted to move too fast and exit Taiwan too early as in the real-time forecast, with only a small improvement in track direction over the Taiwan Strait. With a finer grid in H6A, the predicted 24-h rainfall on 7 August over the southern CMR is also slightly improved (maximum near $1400 \mathrm{~mm}$, not shown). However, only an increase of $250 \mathrm{~mm}$ is predicted on 8 August (not shown) because the TC is predicted to make landfall in China too early at around 0600 UTC (Fig. 10). The predicted total 3-day $(0-72 \mathrm{~h})$ rainfall thus is about $2300 \mathrm{~mm}$ over the southern CMR (Fig. 13a, note that the rainfall scale is up to $3000 \mathrm{~mm}$ ), and is closer to the observed rainfall from 
(a)

.0 TS

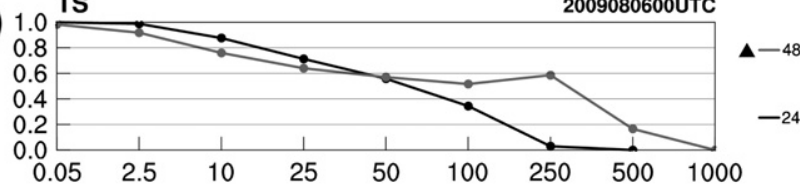

(b) 5.0

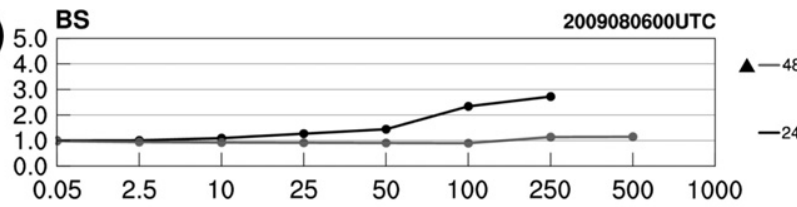

(c)

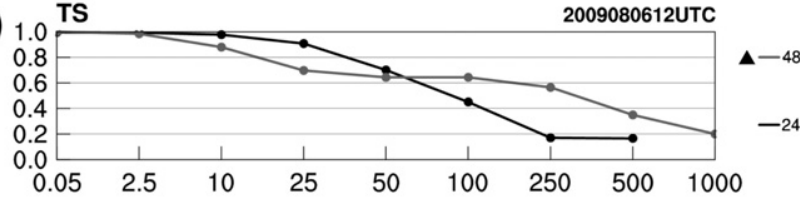

(d) 5.0

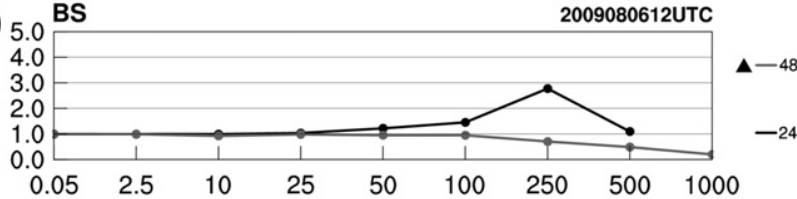

(e)

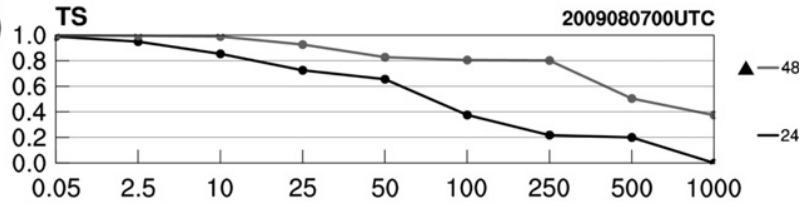

(f)

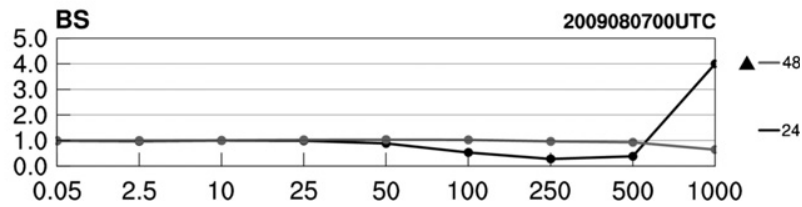

Fig. 12. Skill scores as in Fig. 9, except for (a) TS and (b) BS for the real-time CReSS forecasts in F6A for each 24-h period. (c, d) and (e, f) As in (a, b), except for the F6B and F7A forecasts, respectively. The 24 -h period with the higher rainfall is marked by a solid triangle. the entire event (Fig. 4d) compared to the 2-day forecast in F6A (cf. Fig. 11c), mainly due to the inclusion of the rainfall on the third day. Similarly, the total rainfall over the southwestern plains along $23^{\circ} \mathrm{N}(800-1200 \mathrm{~mm})$ is also higher and closer to the observations, and this is clearly linked to a larger domain extending further upstream and a finer grid as discussed earlier. Thus, a better forecast for Typhoon Morakot was achieved in H6A using a longer range, larger domain, and a finer 3-km grid that reflects more fully the true scale in terms of the total rainfall from the event.

In H6B that is started from 1200 UTC 6 August, the TC is again predicted to exit Taiwan early, but only by about $6-12 \mathrm{~h}$ (Fig. 10). The predicted 3-day rainfall (Fig. 13b) highly resembles the observed rainfall with a slightly larger maximum (about $2400 \mathrm{~mm}$ ) in the mountains and somewhat smaller amounts over the southwestern plains compared to H6A. While the TS and BS values for H6A and H6B (not shown) in the first 2 days are quite similar to those for real-time forecasts F6A and F6B (cf. Fig. 12a-d), they clearly indicate insufficient rainfall production beyond $48 \mathrm{~h}$ that may be primarily attributed to the track error (i.e., early landfall and exit from Taiwan) given in Table 3 (also Fig. 10). However, both the H6A and H6B hindcasts provide high-quality QPFs of the Morakot event, especially the former which gives a longer lead-time.

\section{Discussion}

As shown in previous sections, very useful QPFs in Taiwan were predicted by the CReSS forecasts and hindcasts on 6 August 2009, especially those starting at 0000 UTC (F6A and H6A), even though the TC was predicted to move too fast with the presence of GFS forecast errors (Table 3, Fig. 10). The total rainfall maxima in F6A and H6A (accumulated over 2 and 3 days, respectively) were already $1900-2300 \mathrm{~mm}$, which are about $67-80 \%$ of the observed value (cf. Figs. 4d, 11c, and 13a). Given sufficient computational resources, these results can become available within about $6-8 \mathrm{~h}$ after the initial time, i.e., 1.5-2 days prior to the largest rainrates $\left(\geqslant 20\right.$ or $40 \mathrm{~mm} \mathrm{~h}^{-1}$ ) over the southern CMR, or at least 2.5 days $(60 \mathrm{~h})$ before the Shiao-lin burial (cf. Fig. 5). By contrast, the forecast (F5B) and hindcast (H5B) that started at 1200 UTC 5 August did not have as good a QPF (scores not shown) due to larger track errors where the TC turns northeast early and does not make landfall in Taiwan (Fig. 10 and Table 3). Nevertheless, owing to the surge of southwesterly flow partially enhanced by the TC, the 6day total rainfall maximum in $\mathrm{H} 5 \mathrm{~B}$ exceeds $1400 \mathrm{~mm}$ in the
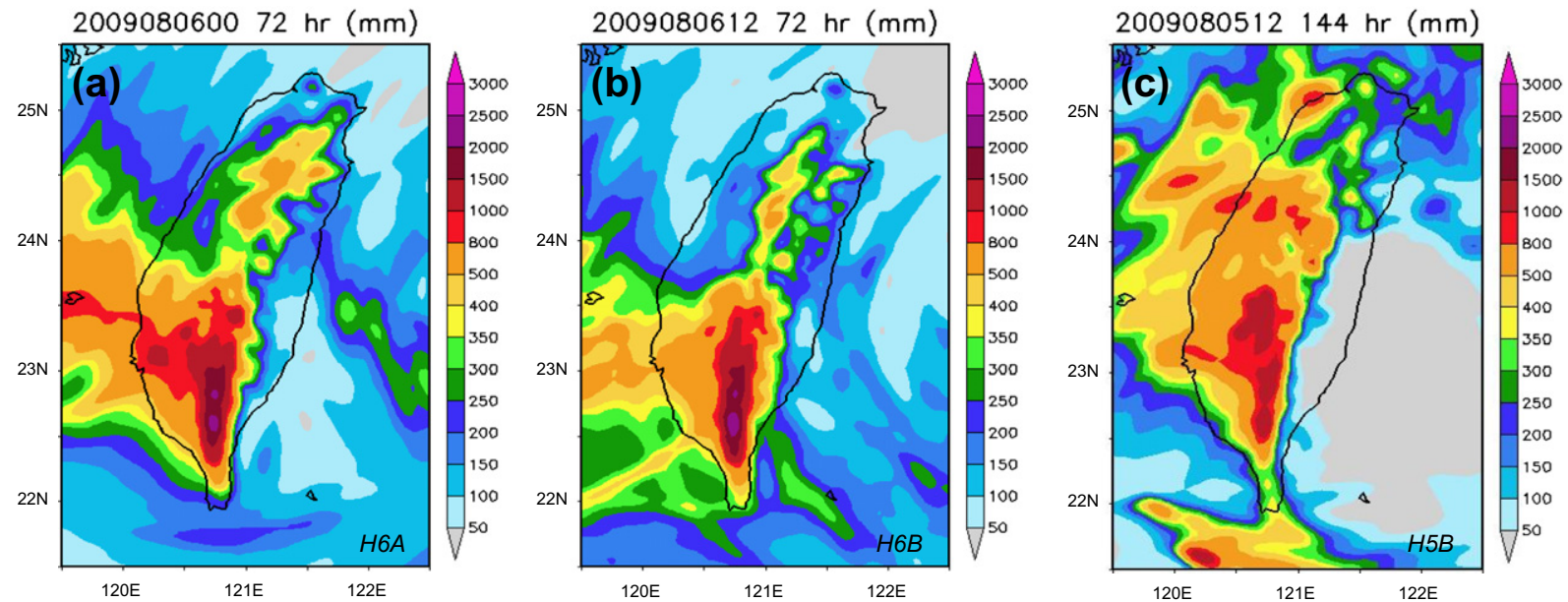

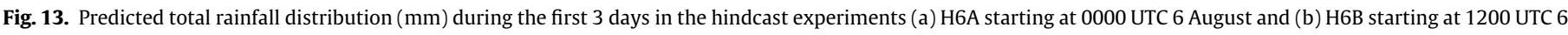
August, and the 6-day total rainfall in (c) H5B starting at 1200 UTC 5 August, 2009. Scales are plotted to the right of each panel. 

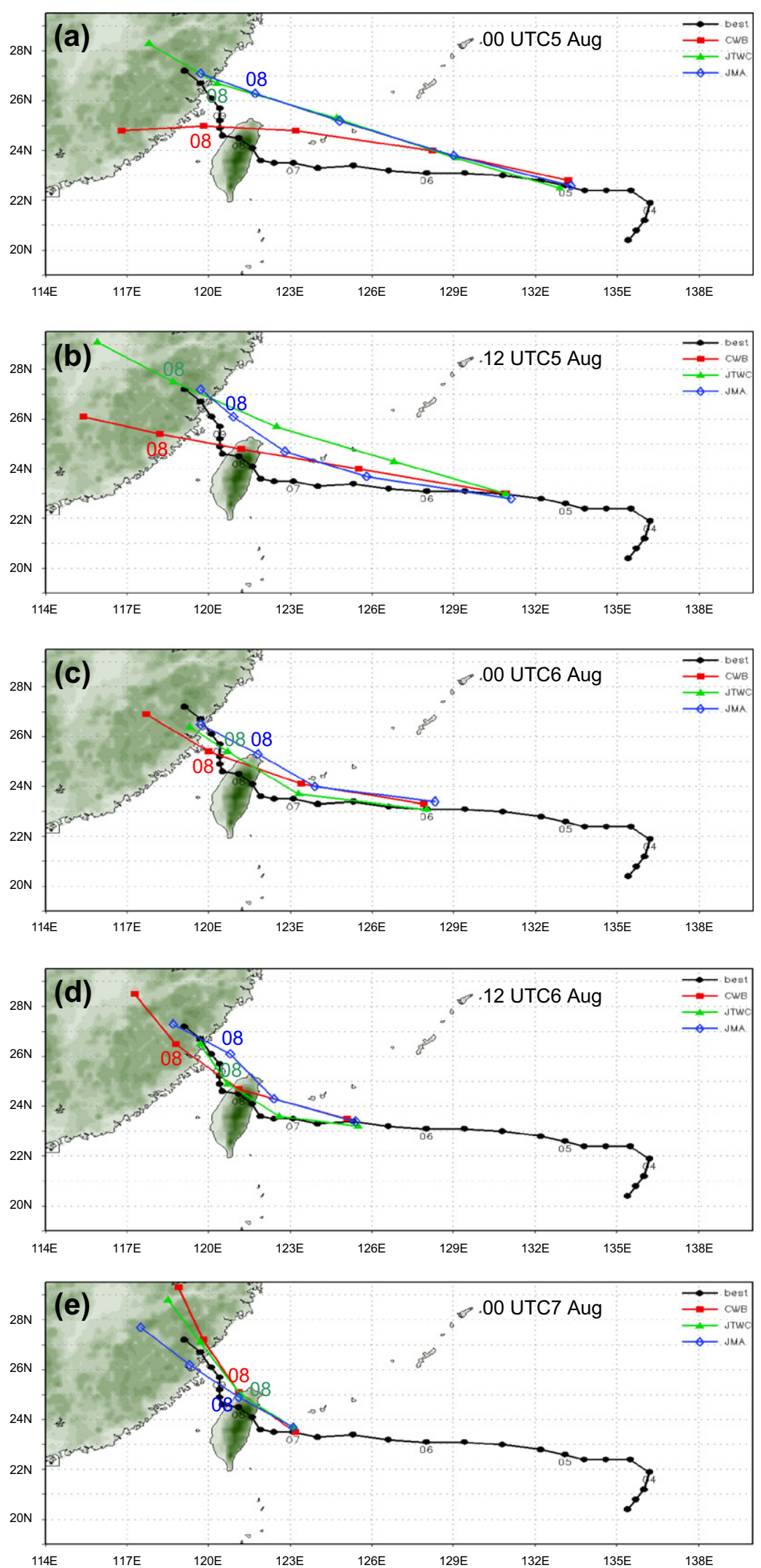

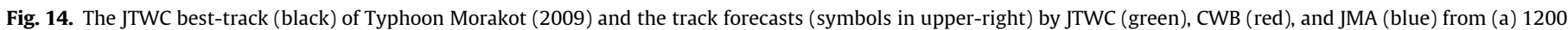

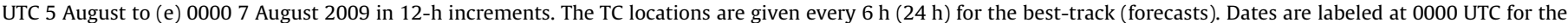
best-track, and at 0000 UTC (a, c, e) or at 1200 UTC (b, d) on 8 August for the forecasts. 

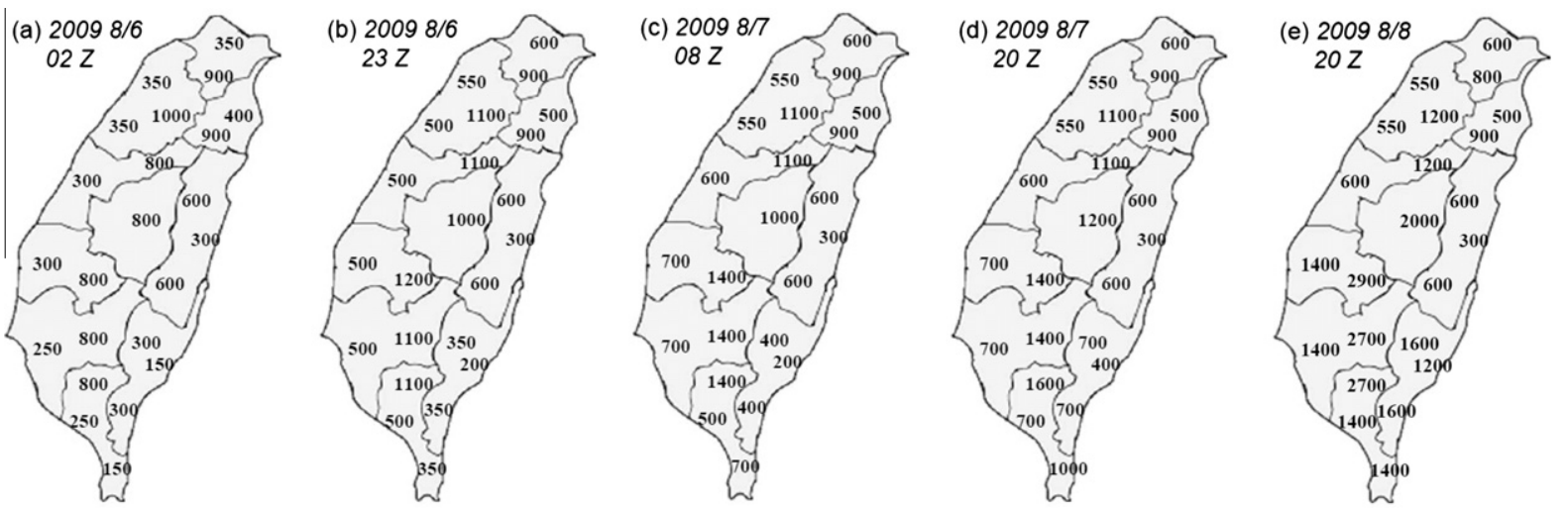

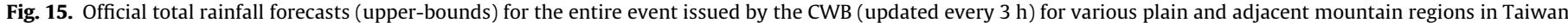
during the warning period of Morakot, released at (a) 0200 UTC and (b) 2300 UTC 6 August, (c) 0800 UTC and 2000 UTC 7 August, and (e) 2000 UTC 8 August 2009.

southern CMR (Fig. 13c), and such an amount is still quite extreme by any standard. Thus, informative results can be obtained at real time even on 5 August.

The track error is considered to be the main error source for QPF in Taiwan, as the rainfall is dictated by the relative position of the TC to the topography through terrain enhancement (also Chang et al., 1993; Lee et al., 2006; Cheung et al., 2008). Even though track errors vary among TC cases and with forecast interval (cf. Table 3), this study of the rainfall in the Morakot event indicates that good QPFs in Taiwan may be obtained by a high-resolution model such as CReSS possibly 4-5 days in advance if the track error is relatively small (as demonstrated by simulations). The large track differences and the resulting QPFs between successive runs at 1200 UTC 5 August and 0000 UTC 6 August (cf. Table 3) highlight the variability between forecasts during the approach of a typhoon, and indicate that it may be misleading to evaluate model performance using skill scores averaged over multiple forecasts and for multiple TCs.

The potential benefits from a high-resolution deterministic model such as CReSS can be illustrated by comparison with the forecasts from major operational centers for the Morakot case. The TC tracks forecast by CWB, JTWC, and the Japan Meteorological Agency (JMA) during 5-7 August 2009 are depicted in Fig. 14. Note that the CWB had predicted the path of the storm better after 0000 UTC 5 August, with a predicted landfall over northern Taiwan. However, none of the three centers adequately forecast the slowdown and sudden change in direction of the storm near Taiwan prior to 1200 UTC 6 August (Fig. 14d), with the JMA (and JTWC) providing the better forecast. In the 0000 UTC 6 August forecast, the TC was forecast to exit Taiwan near 0000 UTC 8 August by JMA, 2000 UTC 7 August by JTWC, and 1800 UTC 7 August by CWB (Fig. 14c), all more or less comparable to the timing in the GFS forecasts and F6A and H6A (cf. Fig. 10). After the 1200 UTC 6 August forecast, the track errors from all three centers at the critical time of 8 August are reduced substantially (Fig. 14d and e, also Table 3), while the northward turn is somewhat better captured in the GFS and H6B forecasts (cf. Fig. 10). As Hendricks et al. (2011) have noted, all regional model tracks are related to the track errors in the parent global model to some extent, and this is true for the CReSS forecasts and hindcasts.

The official rainfall forecasts for the entire event issued by the CWB for various regions in Taiwan were updated every $3 \mathrm{~h}$ as needed, and the CWB upper-bounds at selected times are shown in Fig. 15. For the southern CMR, a maximum of $800 \mathrm{~mm}$ was issued at 0200 UTC 6 August (Fig. 15a), and later updated to $1200 \mathrm{~mm}$ at 2300 UTC 6 August (Fig. 15b), to $1400 \mathrm{~mm}$ and $1600 \mathrm{~mm}$ (twice) on 7 August (Fig. 15c and d), and finally to $2700-2900 \mathrm{~mm}$ at 2000 UTC 8 August (Fig. 15e). For regions in northern Taiwan, the upper-bounds issued on 6 August were near
$1000 \mathrm{~mm}$ and only a few relatively minor adjustments were made (Fig. 15). While a total rainfall of $800 \mathrm{~mm}$ as initially issued (Fig. 15a) would be a serious matter anywhere in the world, this is a deficient amount compared to the forecasts and hindcasts starting from 0000 UTC 6 August (F6A and H6A; cf. Figs. 11c and 13a) and even H5B (cf. Fig. 13c). Although it is not possible to know in real-time operation whether a TC will behave as predicted by the model (mainly in its track), the QPFs from high-resolution deterministic models such as CReSS would provide an indication of the threat, at potentially a considerably longer lead-time with proper real-time verification.

\section{Conclusion and summary}

Using Typhoon Morakot (2009) that brought extreme rainfall up to nearly $3000 \mathrm{~mm}$ to southern Taiwan (mainly over 7-8 August) as an example, in this study it is shown that the CReSS model, a state-of-the-art, high-resolution cloud model, can simulate the event with high accuracy and fidelity, including the distribution and timing of rainfall in Taiwan, at starting time as early as $4 \mathrm{Au}-$ gust, largely owing to the strong phase-locking mechanism of the topography to heavy rainfall. Furthermore, in this event, high-quality QPFs by the CReSS model with peak total rainfall roughly 67$80 \%$ of the true value are also possible at least $1-2$ days prior to the commencement of the heaviest rainfall (or more than 2.5 days before the tragic burial of Shiao-lin Village) in a real-time operational mode. Such forecasts with lead-time are crucial for hazard prevention/reduction in Taiwan, where the steep terrain leads to relatively short concentration time in river runoff.

When properly setup and configured, it is believed that other high-resolution models with similar explicit treatments to cloud microphysics as in CReSS can achieve comparable performance as shown by simulations (e.g., Tao et al., 2011; Nguyen and Chen, 2011). At real time, the key to the success is to predict the TC track relative to the terrain as accurately and as early as possible using one or a small number of high-resolution models. However, since the potential lead-time cannot be realized without an extended forecast range and thus a larger domain (similar to the setting of E6A, for example), this means that sufficient computational resources must be allocated for these deterministic, high-resolution forecasts (Roebber et al., 2004). The requirements of high-resolution, adequate domain size, and longer forecast range all together are challenges for the use of ensemble forecasts with a large number of members to assess model uncertainty in TC-related rainfall (e.g., Buckingham et al., 2010; Zhang et al., 2010; Fang et al., 2011). Therefore, a small number of deterministic models are more affordable in terms of computational demand and more operationally feasible than ensemble forecasts, which can be built by 
gradually adding more members later on. At the time when it matters the most, i.e., just prior to the occurrence of extreme rainfall events, precious time for reaction may be gained from deterministic forecasts as in this study for Typhoon Morakot, which will then lead to reduced losses in human lives and property.

\section{Acknowledgments}

The authors wish to thank Prof. Russ Elsberry of the Naval Postgraduate School and the anonymous reviewers for their constructive comments. Thanks are also to the National Science and Technology Center for Disaster Reduction (NCDR) of Taiwan for providing the radar data used in Fig. 3. The real-time forecast runs in 2009 were carried out on the High-Performance Computer (HPC) of the Chinese Culture University, Taiwan. This study was supported by the National Science Council of Taiwan jointly under Grants NSC-99-2111-M-003-004-MY3, NSC-100-2625-M-003002, NSC-100-2111-M-002-004-MY3, and NSC-101-2625-M-003001.

\section{References}

Asselin, R., 1972. Frequency filter for time integrations. Mon. Weath. Rev. 100, $487-$ 490.

Buckingham, C., Marchok, T., Ginis, I., Rothstein, L., Rowe, D., 2010. Short- and medium-range prediction of tropical and transitioning cyclone tracks within the NCEP Global Ensemble Forecasting System. Weath. Forecast. 25 (6), 17361754.

Chang, C.P., Yeh, T.C., Chen, J.M., 1993. Effects of terrain on the surface structure of typhoons over Taiwan. Mon. Weath. Rev. 121, 734-752.

Charles, M.E., Colle, B.A., 2009. Verification of extratropical cyclones within the NCEP operational models. Part I: analysis errors and short-term NAM and GFS Forecasts. Weath. Forecast. 24 (5), 1173-1190.

Chen, T.C., Yang, Y.S., Wei, C.H., Lin, P.L., Liou, Y.C., Chang, W.Y., Chou, C.B., Ji, B.T. Lin, C.Y., 2010. The precipitation characteristics of Typhoon Morakot (2009) from radar analyses. Atmos. Sci. 38 (1), 39-61 (in Chinese with English abstract).

Cheung, K.K.W., Huang, L.R., Lee, C.S., 2008. Characteristics of rainfall during tropical cyclone periods in Taiwan. Nat. Hazard. Earth Syst. Sci. 8, 1463-1474.

Chien, F.C., Kuo, H.C., 2011. On the extreme rainfall of Typhoon Morakot (2009). J. Geophys. Res. 116, D05104. http://dx.doi.org/10.1029/2010JD015092.

Chien, F.C., Liu, Y.C., Lee, C.S., 2008. Heavy rainfall and southwesterly flow after the leaving of Typhoon Mindulle (2004) from Taiwan. J. Meteorol. Soc. Jpn. 86 (1) $17-41$

Cotton, W.R., Tripoli, G.J., Rauber, R.M., Mulvihill, E.A., 1986. Numerical simulation of the effects of varying ice crystal nucleation rates and aggregation processes on orographic snowfall. J. Clim. Appl. Meteorol. 25, 1658-1680.

Fang, X., Kuo, Y.H., Wang, A., 2011. The impact of Taiwan topography on the predictability of Typhoon Morakot's record-breaking rainfall: a high-resolution ensemble simulation. Weath. Forecast. 26 (5), 613-633.

Fritsch, J.M., Carbone, R.E., 2004. Improving quantitative precipitation forecasts in the warm season. A USWRP research and development strategy. Bull. Am. Meteorol. Soc. 85, 955-965.

Ge, X., Li, T., Zhang, S., Peng, M.S., 2010. What causes the extremely heavy rainfall in Taiwan during Typhoon Morakot (2009)? Atmos. Sci. Lett. 11, 46-50.

Hattori, M., Tsuboki, K., Mori, S., 2010. Contribution of tropical cyclones to the seasonal change patterns of precipitation in the western North Pacific: estimation based on JRA-25/JCDAS. SOLA 6, 100-104.

Hendricks, E.A., Moskaitis, J.R., Jin, Y., Hodur, R.M., Doyle, J.D., Peng, M.S., 2011 Prediction and diagnosis of Typhoon Morakot (2009) using the Naval Research Laboratory's mesoscale tropical cyclone model. Terrest. Atmos. Ocean. Sci. 22 579-594.

Hong, J.S., 2003. Evaluation of the high-resolution model forecasts over the Taiwan area during GIMEX. Weath. Forecast. 18, 836-846.

Hong, C.C., Lee, M.Y., Hsu, H.H., Kuo, J.L., 2010. Role of submonthly disturbance and 40-50 day ISO on the extreme rainfall event associated with Typhoon Morakot (2009) in Southern Taiwan. Geophys. Res. Lett. 37, L08805. http://dx.doi.org/ 10.1029/2010GL042761.

Hsu, J., 1998. ARMTS up and running in Taiwan. Väisälä News 146, 24-26.

Huang, C.Y., Kuo, Y.H., Chen, S.H., Vandenberghe, F., 2005. Improvements in typhoon forecasts with assimilated GPS occultation refractivity. Weath. Forecast. 20, 931-953.

Huang, C.Y., Wong, C.S., Yeh, T.C., 2011. Extreme rainfall mechanisms exhibited by Typhoon Morakot (2009). Terrest. Atmos. Ocean. Sci. 22 (6), 613-632.

Ikawa, M., Saito, K., 1991. Description of a Nonhydrostatic Model Developed at the Forecast Research Department of the MRI. MRI Tech. Rep. 28, 238pp.

Jian, G.J., Wu, C.C., 2008. A numerical study of the track deflection of Supertyphoon Haitang (2005) prior to its landfall in Taiwan. Mon. Weath. Rev. 136, 598-615.
Jou, B.J.D., Yu, Y.C., Feng, L., Chen, Y.M., Lee, C.S., Cheng, M.D., 2010. Synoptic environment and rainfall characteristics of Typhoon Morakot (0908). Atmos. Sci. 38 (1), 21-38 (in Chinese with English abstract).

Kalnay, E., Kanamitsu, M., Baker, W.E., 1990. Global numerical weather prediction at the National Meteorological Center. Bull. Am. Meteorol. Soc. 71, 1410-1428.

Kanamitsu, M., 1989. Description of the NMC global data assimilation and forecast system. Weath. Forecast. 4, 335-342.

Kleist, D.T., Parrish, D.F., Derber, J.C., Treadon, R., Wu, W.S., Lord, S., 2009 Introduction of the GSI into the NCEP global data assimilation system. Weath. Forecast. 24 (6), 1691-1705

Klemp, J.B., Wilhelmson, R.B., 1978. The simulation of three-dimensional convective storm dynamics. J. Atmos. Sci. 35, 1070-1096.

Kondo, J., 1976. Heat balance of the China Sea during the air mass transformation experiment. J. Meteor. Soc. Jpn. 54, 382-398

Kuo, H.C., Yang, Y.T., Chang, C.P., 2010. Typhoon Morakot (2009): Interplay of southwest monsoon, terrain, and mesoscale convection. In: International Workshop on Typhoon Morakot (2009), 24-25 March 2010, Taipei, Taiwan, p. 55.

Lee, C.S., Huang, L.R., Shen, H.S., Wang, S.T., 2006. A climatology model for forecasting typhoon rainfall in Taiwan. Nat. Hazard. 37, 87-105.

Lee, C.S., Liu, Y.C., Chien, F.C., 2008. The secondary low and heavy rainfall associated with Typhoon Mindulle (2004). Mon. Weath. Rev. 136, 1260-1283.

Liang, J., Wu, L., Ge, X., Wu, C.C., 2011. Monsoonal influence on Typhoon Morakot (2009). Part II: numerical study. J. Atmos. Sci. 68, 2222-2235.

Lin, Y.L., Farley, R.D., Orville, H.D., 1983. Bulk parameterization of the snow field in a cloud model. J. Clim. Appl. Meteorol. 22, 1065-1092.

Liu, A.Q., Moore, G.W.K., Tsuboki, K., Renfrew, I.A., 2004. A high-resolution simulation of convective roll clouds during a cold-air outbreak. Geophys. Res. Lett. 31, L03101. http://dx.doi.org/10.1029/2003GL018530.

Louis, J.F., Tiedtke, M., Geleyn, J.F., 1981. A short history of the operational PBL parameterization at ECMWF. In: Workshop on Planetary Boundary Layer Parameterization, 25-27 November 1981. Reading, UK, pp. 59-79.

Maesaka, T., Moore, G.W.K., Liu, Q., Tsuboki, K., 2006. A simulation of a lake effect snowstorm with a cloud resolving numerical model. Geophys. Res. Lett. 33 , L20813. http://dx.doi.org/10.1029/2006GL026638.

Mellor, G.L., Yamada, T., 1974. A hierarchy of turbulent closure models for planetary boundary layers. J. Atmos. Sci. 31, 1791-1806.

Mesinger, F., Black, T.L., 1992. On the impact on forecast accuracy of the stepmountain (eta) vs. sigma coordinate. Meteorol. Atmos. Phys. 50, 47-60.

Moncrieff, M.W., 2010. The multiscale organization of moist convection and the intersection of weather and climate, Climate Dynamics: Why does climate vary? In: D.-Z. Sun (Ed.), Geophysical Monograph Series, vol. 189, American Geophysical Union, pp. 3-26. http://dx.doi.org/10.1029/2008GM000838.

Moorthi, S., Pan, H.L., Caplan, P., 2001. Changes to the 2001 NCEP Operational MRF/ AVN Global Analysis/Forecast System. Tech. Procedures Bull. 484. Office of Meteorology, National Weather Service, 14pp. <http://205.156.54.206/om/tpb/ 484.htm>

Murakami, M., 1990. Numerical modeling of dynamical and microphysical evolution of an isolated convective cloud - the 19 July 1981 CCOPE cloud. J. Meteorol. Soc. Jpn. 68, 107-128.

Murakami, M., Clark, T.L. Hall, W.D. 1994. Numerical simulations of convective snow clouds over the Sea of Japan: two-dimensional simulation of mixed layer development and convective snow cloud formation. J. Meteorol. Soc. Jpn. 72, 43-62.

Nagarajan, B., Yau, M.K., Fillion, L., 2006. A numerical study of the 1996 Saguenay Flood Cyclone: effect of assimilation of precipitation data on quantitative precipitation forecasts. Mon. Weath. Rev. 134, 1371-1388.

Nguyen, H.V., Chen, Y.L., 2011. High resolution initialization and simulations of Typhoon Morakot (2009). Mon. Weath. Rev. 139, 1463-1491.

Reynolds, R.W., Rayner, N.A., Smith, T.M., Stokes, D.C., Wang, W., 2002. An improved in situ and satellite SST analysis for climate. J. Clim. 15, 1609-1625.

Roebber, P.J., Schultz, M.D., Colle, B.A., Stensrud, D.J., 2004. Toward improved prediction: high-resolution and ensemble modeling systems in operations. Weath. Forecast. 19, 936-949.

Segami, A., Kurihara, K., Nakamura, H., Ueno, M., Takano, I., Tatsumi, Y., 1989. Operational mesoscale weather prediction with Japan Spectral Model. J. Meteorol. Soc. Jpn. 67, 907-924.

Tao, W.K., Shi, J.J., Lin, P.L., Chen, J., Lang, S., Chang, M.Y., Yang, M.J., Wu, C.C., PetersLidard, C., Sui, C.H., Jou, B.J.D., 2011. High-resolution numerical simulation of the extreme rainfall associated with Typhoon Morakot. Part I: comparing the impact of microphysics and PBL parameterizations with observations. Terrest. Atmos. Ocean. Sci. 22 (6), 673-696.

Tsuboki, K., Sakakibara, A., 2002. Large-scale parallel computing of cloud resolving storm simulator. In: Zima, H.P. et al. (Eds.), High Performance Computing. Springer, pp. 243-259.

Tsuboki, K., Sakakibara, A., 2007. Numerical prediction of high-impact weather systems. In: The Textbook for Seventeenth IHP Training Course in 2007. HyARC, Nagoya University and UNESCO, 273pp.

Tuleya, R.E., DeMaria, M., Kuligowski, R.J., 2007. Evaluation of GFDL and simple statistical model rainfall forecasts for U.S. landfalling tropical storms. Weath. Forecast. 22 (1), 56-70.

Waliser, D.E., Moncrieff, M.W., 2007. Year of tropical convection-joint WCRPTHORPEX activity to address the challenge of tropical convection. WCRP GEWEX News 17 (2), 8.

Wang, C.C., Huang, W.M., 2009. High-resolution simulation of a nocturnal narrow convective line off the southeastern coast of Taiwan in the Mei-yu season. Geophys. Res. Lett. 36, L06815. http://dx.doi.org/10.1029/2008GL037147. 
Wang, C.C., Chen, G.T.J., Chen, T.C., Tsuboki, K., 2005. A numerical study on the effects of Taiwan topography on a convective line during the Mei-yu season. Mon. Weath. Rev. 133 (11), 3217-3242.

Wang, C.C., Chen, G.T.J., Yang, S.C., Tsuboki, K., 2009. Wintertime supercell thunderstorms in a subtropical environment: numerical simulation. Mon. Weath. Rev. 137 (7), 2175-2202.

Wang, C.C., Chen, G.T.J., Huang, S.Y., 2011. Remote trigger of deep convection by cold outflow over the Taiwan Strait in the Mei-yu season: a modeling study of the 8 June 2007 Case. Mon. Weath. Rev. 139 (9), 2854-2875.

Wang, C.C., Kuo, H.C., Chen, Y.H., Huang, H.L., Chung, C.H., Tsuboki, K., 2012. Effects of asymmetric latent heating on typhoon movement crossing Taiwan: the case of Morakot (2009) with extreme rainfall. J. Atmos. Sci. 69 (11), 3172-3196.

Wilks, D.S., 1995. Statistical Methods in the Atmospheric Sciences. Academic Press, 467pp.

Wu, C.C., Kuo, Y.H., 1999. Typhoons affecting Taiwan: current understanding and future challenges. Bull. Am. Meteorol. Soc. 80 (1), 67-80.
Wu, C.C., Yen, T.H., Kuo, Y.H., Wang, W., 2002. Rainfall simulation associated with Typhoon Herb (1996) near Taiwan. Part I: the topographic effect. Weath. Forecast. 17 (5), 1001-1015.

Wu, C.C., Huang, C.Y., Yang, M.J., Chien, F.C., Hong, J.S., Yen, T.H., 2010. Typhoon Morakot (2009) and a special review on the current status and future challenge of tropical cyclone simulation. Atmos. Sci. 38 (1), 99-134 (in Chinese with English abstract).

Wu, L., Liang, J., Wu, C.C., 2011. Monsoonal influence on Typhoon Morakot (2009). Part I: observational analysis. J. Atmos. Sci. 68 (10), 2208-2221.

Yang, M.J., Zhang, D.L., Huang, H.L., 2008. A modeling study of Typhoon Nari (2001) at landfall. Part I: topographic effects. J. Atmos. Sci. 65 (10), 3095-3115.

Yeh, T.C. Kuo, H.C., Lu, K.C. Wang, S.C., Chen, Y.L., 2010. Verification on the typhoon Morakot track and rainfall forecast issued by the Central Weather Bureau. Atmos. Sci. 38 (1), 85-98 (in Chinese with English abstract).

Zhang, F., Weng, Y., Kuo, Y.H., Whitaker, J.S., Xie, B., 2010. Predicting Typhoon Morakot's catastrophic rainfall with a convection-permitting mesoscale ensemble system. Weath. Forecast. 25 (6), 1816-1825. 